\title{
LDL-Cholesterol-Lowering Therapy
}

\author{
Angela Pirillo, Giuseppe D. Norata, and Alberico L. Catapano
}

\section{Contents}

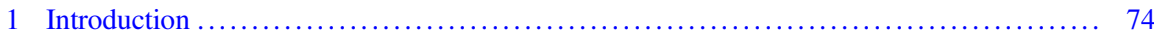

2 Statins in the Prevention of Cardiovascular Disease ............................. 75

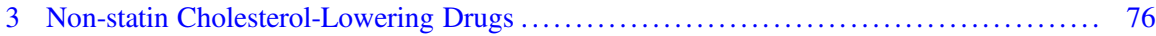

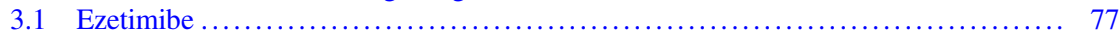

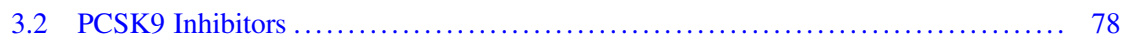

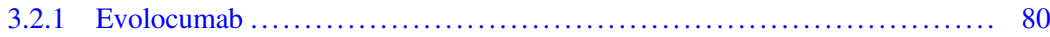

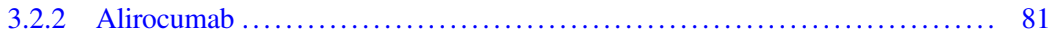

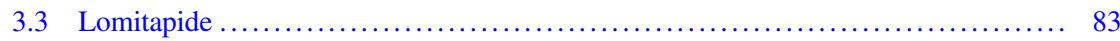

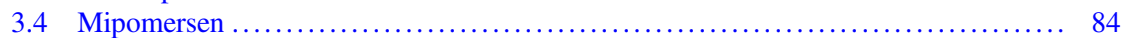

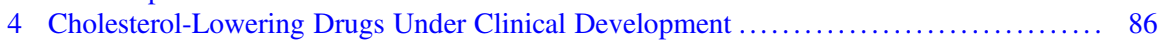

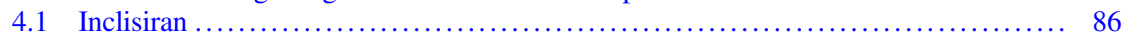

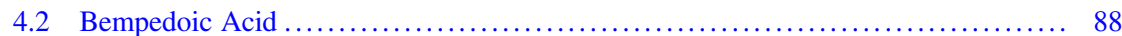

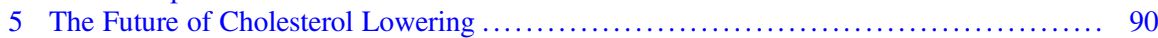

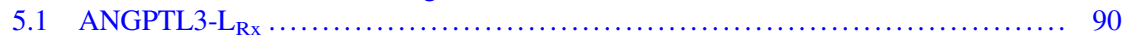

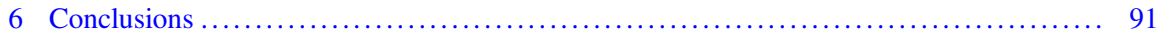

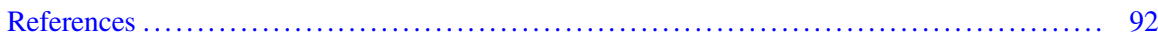

\footnotetext{
A. Pirillo

Center for the Study of Atherosclerosis, E. Bassini Hospital, Milan, Italy

IRCCS MultiMedica, Milan, Italy

e-mail: angela.pirillo@guest.unimi.it

G. D. Norata

Department of Pharmacological and Biomolecular Sciences, Università degli Studi di Milano, Milan, Italy
}

Center for the Study of Atherosclerosis, E. Bassini Hospital, Milan, Italy e-mail: danilo.norata@unimi.it
A. L. Catapano $(\triangle)$ Milan, Italy
IRCCS MultiMedica, Milan, Italy
e-mail: alberico.catapano@unimi.it

Department of Pharmacological and Biomolecular Sciences, Università degli Studi di Milano,

(C) The Author(s) 2020

A. von Eckardstein, C. J. Binder (eds.), Prevention and Treatment of Atherosclerosis,

Handbook of Experimental Pharmacology 270, https://doi.org/10.1007/164_2020_361 


\section{Abstract}

The causal relation between elevated levels of LDL-C and cardiovascular disease has been largely established by experimental and clinical studies. Thus, the reduction of LDL-C levels is a major target for the prevention of cardiovascular disease. In the last decades, statins have been used as the main therapeutic approach to lower plasma cholesterol levels; however, the presence of residual lipid-related cardiovascular risk despite maximal statin therapy raised the need to develop additional lipid-lowering drugs to be used in combination with or in alternative to statins in patients intolerant to the treatment. Several new drugs have been approved which have mechanisms of action different from statins or impact on different lipoprotein classes.

\section{Keywords}

Cardiovascular disease $\cdot$ Dyslipidemias $\cdot$ Ezetimibe $\cdot$ Familial hypercholesterolemia $\cdot$ Hypercholesterolemia $\cdot$ Hypertriglyceridemia $\cdot$ Lipidlowering drugs · Low-density lipoprotein cholesterol $\cdot$ Low-density lipoprotein receptor $\cdot$ Proprotein convertase subtilisin/kexin type $9 \cdot$ Statins

\section{$1 \quad$ Introduction}

Atherosclerosis is a chronic inflammatory disease affecting arterial wall and characterized by a progressive accumulation of lipids in the subendothelial space. Epidemiological and genetic evidence suggests low-density lipoprotein cholesterol (LDL-C) as a causal factor in cardiovascular disease (Ference et al. 2017), and the results of a large number of randomized clinical trials definitely proved that decreasing LDL-C levels translates in a proportional reduction of the risk of atherosclerotic cardiovascular (CV) events (Baigent et al. 2005, 2010, 2011; Cannon et al. 2015a; Sabatine et al. 2017a; Schwartz et al. 2018).

Populations of modern societies present with LDL-C levels largely exceeding those believed to be physiological. Optimal plasma concentration of LDL-C ranges around $25 \mathrm{mg} / \mathrm{dL}$, since above this value the LDL receptor (LDLR) is saturated (Brown and Goldstein 1986); furthermore, individuals with genetically determined low levels of LDL-C are healthy and exhibit very low incidence of CV events (Glueck et al. 1997; Cohen et al. 2006). These observations, coupled to the results of clinical trials testing the most recent lipid-lowering drugs (i.e., PCSK9 inhibitors), which have shown that LDL-C levels may be lowered well below the values recommended by guidelines without safety concerns (Robinson et al. 2017; Sabatine et al. 2017b), provided the notion that reaching very low LDL-C levels may safely confer additional clinical CV benefits. This concept led to a substantial reduction of the LDL-C goals recommended by the most recent guidelines for the management of dyslipidemias (Mach et al. 2020). 
Statins, which represent the cornerstone for the treatment of hypercholesterolemia, have shown approximately a $20 \%$ reduction in the risk of cardiovascular events per each mmol/L LDL-C reduction (Baigent et al. 2005); a more intensive intervention was associated with a greater reduction of the incidence of major vascular events (Baigent et al. 2010), suggesting that the higher the degree of reduction of LDL-C levels, the greater the benefit in terms of reduction of CV events.

Although statin monotherapy could reduce LDL-C levels to a large extent (up to $-50 \%$ with the highest doses of most potent statins), this might not be enough to reach the desired goals based on the individual $\mathrm{CV}$ risk, and therefore additional approaches are needed.

This is even more important in patients with familial hypercholesterolemia (FH) which are considered among those with the highest cardiovascular risk, due to the exposure to high plasma LDL-C levels from birth (Nordestgaard et al. 2013). FH is caused by mutations in genes encoding proteins involved in the LDL catabolism, such as LDL receptor (LDLR), apolipoprotein B (apoB), proprotein convertase subtilisin/kexin type 9 (PCSK9), and LDLR adaptor protein (LDLRAP); mutations in LDLR gene account for the vast majority of FH cases (Nordestgaard et al. 2013). Heterozygous $\mathrm{FH}(\mathrm{HeFH})$ patients are characterized by two- to threefold elevation in plasma cholesterol levels and development of coronary atherosclerosis at an early age (usually after 30 years); homozygous FH (HoFH) patients, which include either patients with a significantly reduced LDLR activity (2-30\% residual activity) or receptor-negative subjects, characterized by a residual LDLR activity $<2 \%$, exhibit a more severe cardiovascular condition, due to the exposure to very high LDL-C levels from birth, childhood coronary heart disease, and premature death from myocardial infarction (prior to 20 years of age) if untreated (Cuchel et al. 2014; Sniderman et al. 2014).

These aspects indicate that the choice of the most appropriate therapeutic approach should be done taking into account the LDL-C target and the distance of LDL-C from the target which are dictated by the cardiovascular risk of the patient, and thus the therapy needs to be tailored to each patient. While statins are the first approach, combination therapy is critical when certain LDL-C goals should be achieved (Norata et al. 2013a; Toth et al. 2016; Russell et al. 2018).

\section{Statins in the Prevention of Cardiovascular Disease}

Statins are competitive inhibitors of 3-hydroxy-3-methylglutaryl coenzyme A (HMG-CoA) reductase, the rate-limiting enzyme of cholesterol synthesis pathway. Following the reduction of intracellular cholesterol synthesis, hepatocytes upregulate surface LDLR expression to increase LDL uptake, resulting in the reduction of circulating LDL-C levels. A large number of clinical trials have established the efficacy of statins in reducing cardiovascular morbidity and mortality in both primary and secondary prevention (Baigent et al. 2010; Chan et al. 2011; Mills et al. 2011a, b; Tonelli et al. 2011; Naci et al. 2013; Taylor et al. 2013). A meta-analysis of 14 randomized clinical trials including $>90,000$ participants 
showed a significant reduction in coronary heart disease (CHD) mortality $(-19 \%$, $p<0.0001)$, myocardial infarction or coronary death $(-23 \%, p<0.0001)$, and fatal or nonfatal stroke $(-17 \%, p<0.0001)$ (Baigent et al. 2005). Overall, there was a significant $21 \%$ proportional reduction in the incidence of major vascular events per $\mathrm{mmol} / \mathrm{L}$ LDL-C reduction (Baigent et al. 2005). A linear relationship between proportional reduction in incidence of major cardiovascular events and mean absolute LDL-C reduction was reported (Baigent et al. 2005). The analysis of more intensive versus less intensive statin regimens showed that treatment with more intensive regimens resulted in an additional 15\% $(p<0.0001)$ reduction in major vascular events (Baigent et al. 2010), suggesting that further reducing LDL-C levels safely translates into a further clinical benefit.

Despite the proven efficacy of statin therapy, a relevant percentage of patients still experience cardiovascular events, even in the presence of well-controlled LDL-C levels due to a "residual risk" (Ahn and Choi 2015), likely related to abnormalities in other lipid parameters (such as high triglycerides and low HDL-c) which may account for this effect particularly in specific groups of patients (including obese patients or those with metabolic syndrome or type 2 diabetes) (Fruchart et al. 2014). Moreover, although statin therapy represents the first approach for the treatment of $\mathrm{FH}$, its efficacy is strictly related to the presence of a functional LDLR and thus may be effective in HeFH or in receptor-defective HoFH (Nordestgaard et al. 2013; Cuchel et al. 2014). In HoFH patients carrying null mutations on LDLR gene, statins induce a modest reduction of LDL-C ( 20\%) likely through pathways LDLRindependent, which however is not sufficient to reduce massively LDL-C levels and reach the goals suggested for their risk category (Hovingh et al. 2013). In addition, although statins are overall well tolerated, statin-associated muscle symptoms may lead to therapy discontinuation and limit clinical benefit (Banach et al. 2015). Muscle-related adverse events occur mainly with high statin doses which are commonly used in high cardiovascular risk patients, but they have been reported also in patients presenting with comorbidities, due to pharmacokinetic interactions with other drugs (Chatzizisis et al. 2010; Taha et al. 2014). Several pharmacological approaches are available for the management of hypercholesterolemia in patients intolerant to statins, including the possibility to combine a low dose of a statin with another cholesterol-lowering drug which is acting by a complementary mechanism of action (Pirillo and Catapano 2015). Several non-statin drugs approved for the treatment of dyslipidemia, however, failed to further reduce the incidence of cardiovascular events when added to current statin therapy, with the exception of ezetimibe (Ridker 2014; Cannon et al. 2015a) and, more recently, PCSK9 inhibitors (Sabatine et al. 2017a; Schwartz et al. 2018).

\section{$3 \quad$ Non-statin Cholesterol-Lowering Drugs}

In recent years several therapeutic approaches have been investigated and developed with the aim of reducing plasma cholesterol levels with a mechanism of action complementary to that of statins. Among them, ezetimibe and, more recently, the 
monoclonal antibodies targeting PCSK9 have been approved, while other molecules including bempedoic acid and PCSK9 gene silencing are in an advanced phase of clinical development.

\subsection{Ezetimibe}

Ezetimibe is a lipid-lowering drug acting as an inhibitor of intestinal cholesterol absorption through the inhibition of the sterol transporter Niemann-Pick C1L1 (NPC1L1) protein (Davis and Veltri 2007). This protein, highly expressed at the brushborder membrane of intestinal epithelial cells, plays a central role in the intestinal absorption of cholesterol and the regulation of cholesterol plasma levels (Wang 2007; Wang and Song 2012). The observation that individuals carrying lossof-function variants in NPC1L1 have lower LDL-C levels and a 53\% relative risk reduction of CHD (Stitziel et al. 2014) has suggested that this protein could represent a potential pharmacological target for the treatment of hypercholesterolemia.

Ezetimibe has a complementary mechanism of action as compared to statins. Statins, by inhibiting cholesterol synthesis pathway, induce the upregulation of hepatic LDLR, thus resulting in increased uptake of LDL particle from the circulation. This effect prompts a feedback mechanism which increases cholesterol absorption in the intestine, thus partially affecting the efficacy of statin therapy. In this context, ezetimibe as monotherapy, by inhibiting intestinal cholesterol absorption, will reduce plasma cholesterol levels, but the effect would be mitigated by the induction of increased cholesterol synthesis in the intestine and the liver (Descamps et al. 2011). Therefore, the combination statin+ezetimibe will reduce both cholesterol synthesis and absorption, thus representing a valuable approach for further reducing plasma LDL-C levels beyond what was observed with statins in monotherapy.

Indeed several clinical trials have shown that adding ezetimibe to statin therapy results in a further 15-20\% LDL-C level reduction (Catapano et al. 2005, 2006; Mikhailidis et al. 2007; Norata et al. 2013a). A pooled analysis of over 21,000 subjects from 27 clinical trials showed that co-administration of ezetimibe with a statin produces a greater LDL-C-lowering effect than statin alone in a wide range of patients (Morrone et al. 2012). Furthermore, the reduction in LDL-C levels was more impressive in patients with CHD or CHD risk-equivalents treated with ezetimibe added to current statin dose compared with patients who titrated the statin dose (Foody et al. 2013). This difference has been reported also in diabetic patients treated with ezetimibe+statin, who showed a $24.6 \%$ LDL-C reduction compared with a $10.9 \%$ reduction observed in those receiving a doubled statin dose; similarly the entire lipid profile was improved more in patients receiving the combination therapy (Sakamoto et al. 2015). A meta-analysis of available randomized clinical trials showed that the addition of ezetimibe to ongoing simvastatin, atorvastatin, or rosuvastatin therapy results in a greater reduction of LDL-C in high CV risk patients compared with doubling the statin dose (Lorenzi et al. 2019). 
The combination ezetimibe+statin has been shown to be effective also in FH patients with residual LDLR activity, who achieve lower levels of total cholesterol and LDL-C than patients treated with statin alone (Gagne et al. 2002; Pisciotta et al. 2007; Kastelein et al. 2008).

Adding ezetimibe to statin therapy was also shown to provide a clinical benefit. The SHARP trial showed that ezetimibe+simvastatin administration for 4.9 years in patients with moderate-to-severe kidney disease reduced LDL-C levels by $0.85 \mathrm{mmol} / \mathrm{L}(33 \mathrm{mg} / \mathrm{dL})$ and decreased the incidence of first major atherosclerotic events (including nonfatal MI, coronary death, non-hemorrhagic stroke, or arterial revascularization) by 17\% compared with placebo (Baigent et al. 2011). The IMPROVE-IT trial compared the effect of a 6-year administration of ezetimibe +simvastatin or simvastatin alone in patients with a recent acute coronary syndrome (Cannon et al. 2015a). The combination therapy reduced LDL-C level more than simvastatin alone (24\% further reduction), resulting in a significant $6.4 \%$ lower relative risk reduction of the primary composite endpoint (cardiovascular death, nonfatal myocardial infarction, unstable angina requiring hospitalization, coronary revascularization, nonfatal stroke) (Cannon et al. 2015a). Specific subgroups of patients benefit more from the combination therapy, including women (12\% reduction of the relative CV vs 5\% in men) (Toda Kato et al. 2015), older patients ( $<65$ years HR $0.98 ; \geq 75$ years HR: 0.80 ), and diabetic patients $(15 \%$ reduction versus $2 \%$ in non-diabetics) (Giugliano et al. 2018). Combined therapy was also superior to simvastatin alone in reducing the incidence of non-hemorrhagic stroke (hazard ratio 0.78, $P=0.008$ ) (Wiviott et al. 2015). Adverse event incidence was similar in all subgroups (Wiviott et al. 2015).

\subsection{PCSK9 Inhibitors}

Proprotein convertase subtilisin kexin 9 (PCSK9) is a serine protease involved in the regulation of hepatic low-density lipoprotein receptor (LDLR) expression and, as a consequence, in the control of plasma LDL-C levels (Fig. 1). In fact, secreted PCSK9 binds to LDLR, and when the complex LDLR/PCSK9 is internalized, the conformational change of LDLR induced by PCSK9 impairs LDLR recycling on cell surface while making it more susceptible to degradation within lysosomes. This leads to a reduced LDLR surface expression, reduced LDL uptake, and therefore increased LDL-C plasma levels (Leren 2014; Norata et al. 2016; Seidah et al. 2019). Individuals carrying loss-of-function mutations in PCSK9 gene have lower levels of LDL-C and reduced risk of cardiovascular disease (Cohen et al. 2005, 2006; Kathiresan 2008; Benn et al. 2010; Kent et al. 2017), while gain-of-function mutations are associated with an increased risk of premature cardiovascular disease (Naoumova et al. 2005; Hopkins et al. 2015; Qiu et al. 2017). Based on these observations, PCSK9 inhibition has been suggested as a possible approach for the control of hypercholesterolemia (Fig. 1).

Despite the liver is the major organ expressing PCSK9, other tissues express this protein, including the kidney, pancreas, and brain (Norata et al. 2016); this 


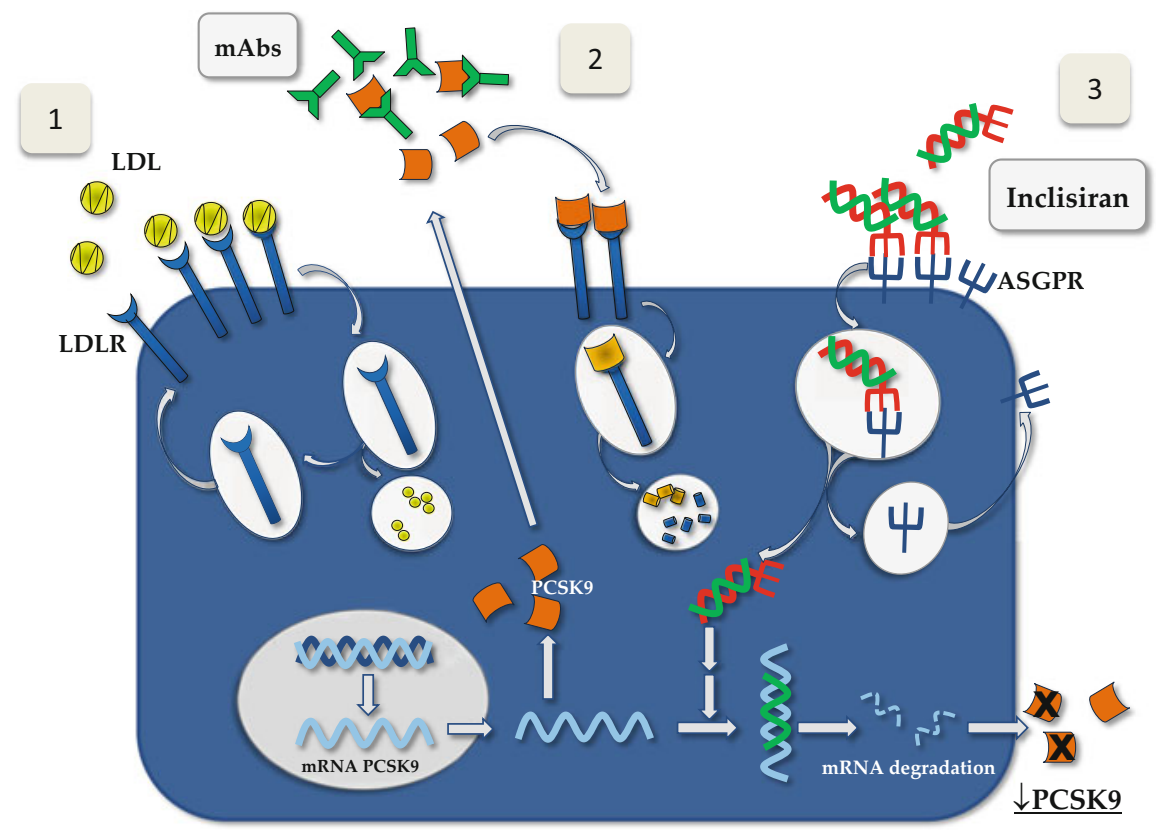

Fig. 1 Mechanism of action of PCSK9 inhibitors. In the absence of PCSK9 (1), LDL binds to LDLR. After internalization, the LDL-LDLR complex dissociates, LDL undergoes lysosomal degradation, and LDLR is recycled to the cell surface. In the presence of PCSK9 (2), LDLR cannot dissociate from LDL and is degraded within the lysosomes, leading to increased levels of circulating LDL-C. Monoclonal antibodies (mAbs) neutralize secreted PCSK9, thus inhibiting its binding to the LDLR and dampening PCSK9-induced LDLR degradation. Inclisiran (3) is a siRNA which is internalized by specific hepatic receptors (ASGPR1) and acts intracellularly by binding to PCSK9 mRNA, thus inducing its degradation and reducing the production of the protein. LDL, low-density lipoprotein; LDLR, LDL receptor; PCSK9, proprotein convertase subtilisin/kexin type 9

observation raises the question of whether the pharmacological inhibition of PCSK9 may also result in extrahepatic effects with a clinical relevance. PCSK9 deficiency in animal models and loss-of-function mutations in humans were associated with increased risk of new-onset diabetes (Ference et al. 2016; Da Dalt et al. 2019), pointing to a role for PCSK9 and LDLR on cholesterol metabolism in pancreatic beta cells (Perego et al. 2019). Available data from clinical trials with anti-PCSK9 monoclonal antibodies excluded this hypothesis (Sabatine et al. 2017a; Schwartz et al. 2018); data from long-term post-marketing surveillance are awaited to clarify this aspect.

Different approaches have been tested or are under evaluation for targeting PCSK9 (Seidah et al. 2019), including two fully human monoclonal antibodies against circulating PCSK9, evolocumab and alirocumab, which inhibit the activity of secreted PCSK9 (approved for the treatment of hypercholesterolemia), and, more recently, a small interfering RNA approach which inhibits PCSK9 synthesis in the liver now under clinical evaluation. 


\subsubsection{Evolocumab}

Several phase 2 trials have shown that evolocumab efficiently reduces LDL-C levels in hypercholesterolemic subjects either as monotherapy or as add-on to background lipid-lowering therapy (LLT) (Giugliano et al. 2012; Koren et al. 2012) and was effective also in FH patients (Raal et al. 2012; Stein et al. 2013) and in statinintolerant patients (Sullivan et al. 2012).

The PROFICIO (Program to Reduce LDL-C and Cardiovascular Outcomes Following Inhibition of PCSK9 in Different Populations) program of evolocumab included phase 3 clinical trials aimed at assessing the effectiveness of evolocumab in comparison with placebo or ezetimibe across a broad population of patients with hypercholesterolemia. In monotherapy, evolocumab efficiently reduced LDL-C levels compared with either placebo or ezetimibe (Koren et al. 2014); when added to a moderate- or high-intensity statin therapy, evolocumab reduced LDL-C levels more efficiently than adding placebo or ezetimibe, and most patients achieved LDL-C levels $<70 \mathrm{mg} / \mathrm{dL}$, compared with the group receiving ezetimibe (Robinson et al. 2014). Similar results were obtained when hypercholesterolemic patients were treated for 52 weeks with evolocumab added to different lipid-lowering therapy with a significant $57 \%$ LDL-C level reduction that was maintained throughout the study period, independent of background therapy (Blom et al. 2014). Evolocumab also induced a decrease in percent atheroma volume (PAV) in statin-treated patients (Nicholls et al. 2016).

The efficacy of PCSK9 has been tested also in patients with statin intolerance. In the phase 3 GAUSS-2 study, statin-intolerant patients were treated with evolocumab or ezetimibe for 12 weeks: evolocumab reduced LDL-C levels more efficiently than ezetimibe, and the incidence of myalgia among treated patients was low (Stroes et al. 2014). These findings have been confirmed by the GAUSS-3 trial (Nissen et al. 2016).

Specific studies have evaluated the effect of evolocumab also in FH patients (Raal et al. 2012, 2015b). The RUTHERFORD-2 study showed a significant reduction of LDL-C levels ( $60 \%$ ) in HeFH patients treated with evolocumab (Raal et al. 2015b). The pilot study TESLA part A, performed in six receptor-defective and two receptornegative HoFH patients, showed that patients with defective LDLR activity had a significant reduction in their LDL-C levels following the treatment with evolocumab $(\sim 23 \%)$, while, as expected on the basis of the mechanism of action, receptornegative patients did not respond to the therapy (Stein et al. 2013) further confirming that the mechanism by which evolocumab reduces LDL-C levels is primarily through the upregulation of residual LDLR activity. In the phase 3 TESLA part $\mathrm{B}$ trial, a $\sim 31 \%$ LDL-C reduction was observed; the analysis of LDL-C reduction according to LDLR mutation status showed that the type of mutation causing $\mathrm{FH}$ is the major determinant of evolocumab-induced response (Raal et al. 2015a). An interim analysis of the open-label TAUSSIG trial confirmed that evolocumab reduces LDL-C levels by approximately $20 \%$ in $\mathrm{HoFH}$ patients (with the exception of receptor-negative patients), a reduction that persisted up to 48 weeks, with a high variability in the percent change of LDL-C from baseline (Raal et al. 2017). 
Patients who completed one of the phase 2 or 3 studies have been recruited for the open-label trials OSLER-1 (for phase 2) and OSLER-2 (for phase 3); the analysis of combined data showed that evolocumab reduced LDL-C levels by $61 \%$ compared with patients treated with standard therapy; this reduction was sustained through 48 weeks and translated into a lower rate of all CV events (Sabatine et al. 2015). The final report of the OSLER-1 study showed a persistent LDL-C reduction over 5 years with a good safety profile (Koren et al. 2019). The benefit of this massive LDL-C reduction translated also in a clinical benefit. Indeed the FOURIER trial showed that, after a median follow-up of 2.2 years, in statin-treated patients with CVD and LDL-C $\geq 70 \mathrm{mg} / \mathrm{dL}$, evolocumab significantly reduced by $15 \%$ the risk of the primary endpoint (including cardiovascular death, myocardial infarction, stroke, hospitalization for unstable angina, or coronary revascularization) and by $20 \%$ the secondary endpoint (cardiovascular death, myocardial infarction, or stroke) (Sabatine et al. 2017a). The clinical benefit was present in all patient categories, with patients at the highest $\mathrm{CV}$ risk showing the greatest absolute risk reduction (Sabatine et al. 2017b, 2018; Bonaca et al. 2018). A prespecified analysis of the FOURIER trial showed a linear relationship between LDL-C levels and CV outcomes down to LDL-C $<0.5 \mathrm{mmol} / \mathrm{L}(<\sim 20 \mathrm{mg} / \mathrm{dL})$, without safety concerns (Giugliano et al. 2017b). The therapy with evolocumab did not increase the risk of new-onset diabetes and did not worsen glycemia (Sabatine et al. 2017b) nor did affect negatively the cognitive function (Giugliano et al. 2017a). Altogether these results indicate that evolocumab can be used safely used to reduce LDL-C levels and the risk of $\mathrm{CV}$ events in patients at high $\mathrm{CV}$ risk despite current optimized lipidlowering therapy.

\subsubsection{Alirocumab}

Alirocumab is a fully human monoclonal antibody against PCSK9. As for evolocumab, several phase 2 trials have been performed in different patient groups; these trials have reported a significant alirocumab-induced reduction of LDL-C levels in patients taking statins as well as in patients with $\mathrm{FH}$ (40\% up to $73 \%$ ) (McKenney et al. 2012; Roth et al. 2012; Stein et al. 2012b; Dufour et al. 2017).

The ODYSSEY program included 14 phase 3 trials on alirocumab, aimed at evaluating the efficacy and safety of alirocumab alone or in combination with other lipid-lowering therapies in different groups of hypercholesterolemic patients. As monotherapy, alirocumab reduced LDL-C levels more efficiently than ezetimibe (47.2\% vs $15.6 \%$ ) (Roth and McKenney 2015). Then alirocumab was tested in high $\mathrm{CV}$ risk populations as add-on to maximum tolerated statin \pm other LLT: the COMBO I and II studies showed that alirocumab induced a greater reduction of LDL-C levels compared with either placebo (48.2\% vs 2.3\%) (Kereiakes et al. 2015) or ezetimibe (50.6\% vs $20.7 \%$ ) (Cannon et al. 2015b). In the ODYSSEY LONG TERM trial, the addition of alirocumab to the maximal tolerated dose of statin produced a $61 \%$ reduction of LDL-C levels at week 24 , and this reduction persisted up to week 78 (52.4\%) (Robinson et al. 2015). Adjudicated major CV events in a post hoc analysis were lower in alirocumab group than in placebo group (1.7\% vs $3.3 \%$ ), with cumulative probability of event curves tending to diverge over time 
(Robinson et al. 2015). The ODYSSEY OPTIONS I and II trials compared the effects of adding alirocumab to atorvastatin or rosuvastatin, adding ezetimibe, or doubling the statin dose; these trials reported the greatest LDL-C level reductions in patients treated with alirocumab as add-on (Bays et al. 2015; Farnier et al. 2016).

A specific trial was designed to address the efficacy and safety of alirocumab in statin-intolerant patients, with a statin rechallenge arm. In the ODYSSEY ALTERNATIVE trial, alirocumab produced greater LDL-C reduction compared with ezetimibe in patients intolerant to statins ( $45 \%$ and $14.6 \%$ at week 24 , respectively), and a higher percentage of patients reached the recommended LDL-C goal $(41.9 \%$ vs $4.4 \%$, respectively) (Moriarty et al. 2015). Skeletal muscle-related adverse events were the most common in all treatment groups, but significantly lower with alirocumab vs atorvastatin (HR 0.61, 95\% CI, 0.38-0.99, $P=0.042$ ) (Moriarty et al. 2015).

The ODYSSEY program included also clinical trials specifically designed to evaluate the effect of alirocumab in HeFH patients. In the ODYSSEY FH I (North America, Europe, South Africa) and FH II (Europe) studies, HeFH patients with an inadequate control of LDL-C levels despite maximally tolerated LLT received alirocumab and showed 57.9\% (FH I) and 51.4\% (FH II) LDL-C level reductions with alirocumab versus placebo; these reductions were maintained up to week 78 (Kastelein et al. 2015). Similar reductions were observed in HeFH patients presenting with higher LDL-C levels $(\geq 4.1 \mathrm{mmol} / \mathrm{L} ; \geq 160 \mathrm{mg} / \mathrm{dL})$ despite maximally tolerated LLT, in agreement with previous observations (Kastelein et al. 2014; Robinson et al. 2015). The treatment with alirocumab allowed the discontinuation or, at least, prolonged the time to next apheresis treatment in $\mathrm{HeFH}$ patients undergoing weekly or biweekly lipoprotein apheresis at baseline (ODYSSEY ESCAPE trial) (Moriarty et al. 2016). The ODYSSEY OLE study, which included HeFH patients who had completed one of the four phase 3 parent studies (FH I, FH II, LONG TERM, HIGH FH), showed a durability of alirocumab-induced LDL-C lowering over time (Farnier et al. 2018).

The ODYSSEY OUTCOMES trial tested the hypothesis that the treatment with alirocumab may reduce the risk of $\mathrm{CV}$ events in patients with a recent acute coronary syndrome having LDL-C levels exceeding the recommended goals for this risk category despite high-intensity statin therapy (Schwartz et al. 2018). After a median follow-up of 2.8 years, the risk of composite primary endpoint was significantly reduced by $15 \%$ in alirocumab-treated patients, and the greatest absolute reduction was observed in patients with the highest baseline LDL-C levels $(\geq 100 \mathrm{mg} / \mathrm{dL}$ ) (Schwartz et al. 2018). During the study, LDL-C levels were reduced by $62.7 \%$ at 4 months and $54.7 \%$ at 48 months (Schwartz et al. 2018).

Altogether, the results obtained in these studies have shown a significant efficacy of this pharmacological approach, which, by inducing a remarkable and sustained reduction of LDL-C levels beyond that obtained with statins with/without other LLT, translates into a greater CV benefit. 


\subsection{Lomitapide}

Microsomal triglyceride transfer protein (MTP) localizes in the endoplasmic reticulum (ER) of hepatocytes and enterocytes and acts by transferring triglycerides and cholesteryl esters from the ER membrane to the nascent apoB (Hooper et al. 2015) (Fig. 2). MTP plays an essential role in the assembly and secretion of apolipoprotein B-containing lipoproteins, including very-low-density lipoproteins (VLDL) and chylomicrons (Hooper et al. 2015). Loss-of-function mutations in the gene encoding for MTP $(M T T P)$ result in a reduced synthesis of VLDL and chylomicrons, increased apoB degradation, and lower levels of circulating LDL-C; based on these observations, MTP has been proposed as a possible target for the pharmacological control of hypercholesterolemia, particularly for the treatment of HoFH (Sirtori et al. 2014). Lomitapide is an MTP inhibitor which reduces LDL-C levels independent of LDLR (Fig. 2), and preclinical studies in animal models have shown that MTP inhibition resulted in the reduction of atherogenic lipoprotein levels (Wetterau et al. 1998; Shiomi and Ito 2001).

Lomitapide has been approved for the treatment of HoFH (Berberich and Hegele 2017), based on the results of several randomized clinical trials. A phase 2 study showed that the administration of lomitapide for 16 weeks in monotherapy efficiently reduced LDL-C levels in six HoFH patients (5 LDLR-negative and 1 LDLRdefective) (Cuchel et al. 2007); overall the drug was well tolerated, and the most serious adverse events were elevations in liver aminotransferase levels and hepatic fat accumulation (Cuchel et al. 2007). This study highlighted that, although lomitapide was highly effective in reducing LDL-C levels, it also induced liver steatosis in treated patients, casting doubts about long-term safety.

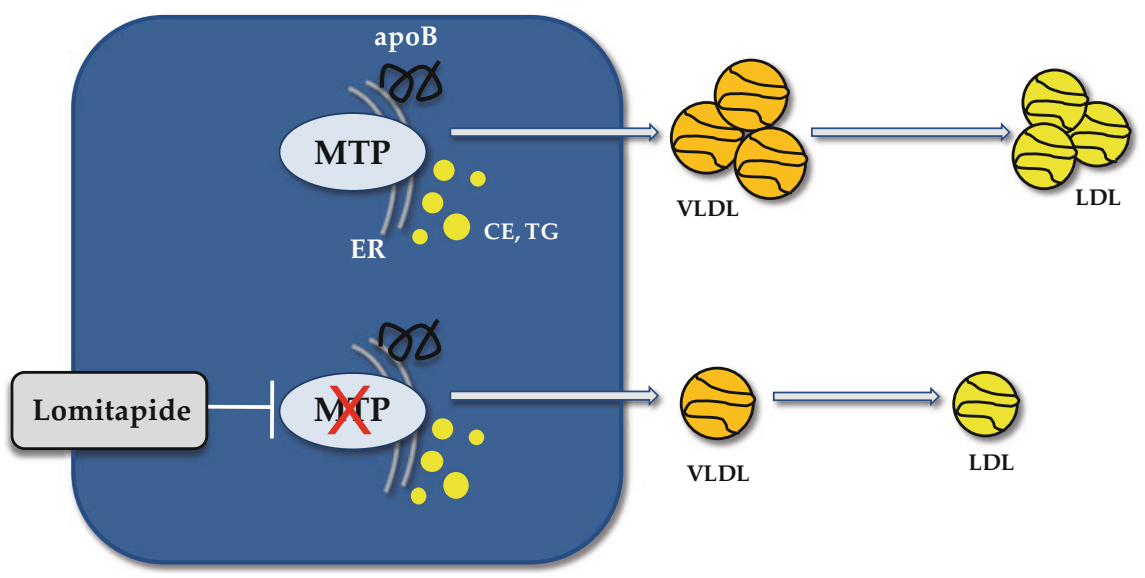

Fig. 2 Mode of action of lomitapide. MTP mediates the transfer of cholesteryl esters (CE) and triglycerides (TG) to apolipoprotein $\mathrm{B}(\mathrm{apoB})$ resulting in the synthesis of VLDL and chylomicrons. Lomitapide inhibits the activity of MTP, thus reducing the production of apoB-containing lipoproteins 
To address this aspect, lomitapide was administered to $29 \mathrm{HoFH}$ patients in a single-arm, open-label, phase 3 study in addition to conventional lipid-lowering therapy (Cuchel et al. 2013). Mean LDL-C levels were significantly reduced by $50 \%$ at the end of efficacy phase (week 26) with some patients able to discontinue or increase the interval between apheresis treatments (Cuchel et al. 2013). At the end of the study (week 78), LDL-C reduction was partially attenuated (-38\%); changes in the concomitant lipid-lowering therapies or adjustment of the lomitapide dose in patients experiencing adverse effects can likely explain this result (Cuchel et al. 2013). Many patients reported gastrointestinal adverse reactions, which were controlled by moving patients on a very-low-fat diet. Increased levels of ALT, AST, or both, observed in some patients, were transient, successfully managed by dose reduction or temporary interruption, and were not related to changes of liver function. A modest increase (8.6\%) in hepatic fat content was observed (Cuchel et al. 2013); the clinical consequence of this rise in liver fat is still unclear and requires further investigation with longer-term trials in a higher number of patients to assess whether it could have metabolic consequences.

Data from the real-world setting seem to suggest that safety profile of lomitapide is similar to that reported by clinical trials and have confirmed the need of a careful monitoring of transaminase levels and the adherence to a low-fat diet which may minimize gastrointestinal side effects (Roeters van Lennep et al. 2015). A longer follow-up is required to further support safety and establish whether lomitapide therapy may translate into a clinical cardiovascular benefit. To this aim, the LOWER registry for patients treated with lomitapide was created (Blom et al. 2016); it also includes the CAPTURE substudy which is aimed at investigating the effect of lomitapide on the atheroma regression and/or stabilization in the carotid artery and aorta (Blom et al. 2016).

Lomitapide is a weak inhibitor of CYP3A4, thus it might decrease statin metabolism (Tuteja et al. 2014), and therefore careful monitoring for adverse events when these two drugs are administered in combination is required.

\subsection{Mipomersen}

Elevated levels of apoB, the main apoprotein of all atherogenic lipoproteins, represent an established risk factor in atherosclerosis; mutations in apoB gene causing familial hypobetalipoproteinemia, characterized by very low levels of apoB and LDL-C, have been associated with a reduced risk of coronary disease (Peloso et al. 2019). Furthermore, a Mendelian randomization study showed that genetic variants resulting in reduced apoB levels are associated with comparable lower CHD risk per unit difference in apoB (Ference et al. 2019a), strengthening the concept that the clinical benefit of lipid-lowering therapies may be proportional to the absolute change in apoB levels. Thus, apoB may be a pharmacological target to reduce hypercholesterolemia.

In parallel with the possibility to inhibit MTP activity, it is also possible to target the key structural protein of VLDL and LDL to inhibit lipoprotein biosynthesis 


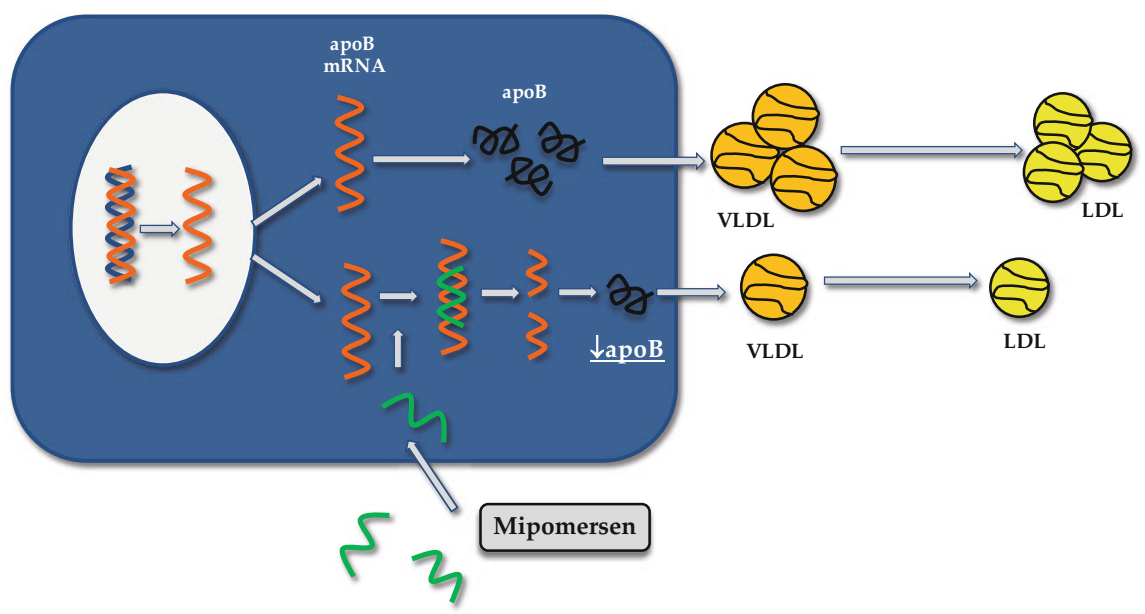

Fig. 3 Mechanism of action of mipomersen. Mipomersen is an antisense oligonucleotide (ASO) that inhibits the synthesis of apolipoprotein B. It binds to the cognate mRNA forming a substrate for a nuclease, thus resulting in mRNA degradation and reduced production of apoB and apoBcontaining lipoproteins

(Norata et al. 2013a). Mipomersen is a second-generation antisense oligonucleotide against the coding region of human apolipoprotein B mRNA which, by silencing apoB, results in the reduction of all apoB-containing lipoproteins. The effect of mipomersen is independent of LDLR and thus represents a suitable approach for the treatment of FH with severe LDLR mutations (Crooke and Geary 2013) (Fig. 3). Several trials have shown the lipid-lowering efficacy of mipomersen either as monotherapy or as add-on to current lipid-lowering therapies (Kastelein et al. 2006; Akdim et al. 2010a, b, 2011; Raal et al. 2010; McGowan et al. 2012; Stein et al. 2012a; Visser et al. 2012). A recent meta-analysis on data from 13 randomized clinical trials confirmed that mipomersen significantly reduced LDL-C levels by $26 \%$, with an overall improvement of all lipid parameters (Fogacci et al. 2019). Nevertheless, mipomersen therapy was associated with several side effects such as injection site reactions, flu-like symptoms, hepatic steatosis, and hepatic enzyme elevations which lead to an elevated number of patients discontinuing the treatment (Fogacci et al. 2019).

The most important side effect expected from the mechanism of action is an increased content of TG in the liver which raised some concerns regarding mipomersen therapy. While short-term studies have in fact reported increased steatosis in mipomersen-treated patients, longer-term trials (up to 104 weeks) showed a return to normal of hepatic triglyceride levels (Sahebkar and Watts 2013; Toth 2013). Further, the analysis of liver biopsies from mipomersen-treated patients revealed a histopathological feature of simple steatosis without signs of inflammation or fibrosis (Hashemi et al. 2014). 
In $\mathrm{HeFH}$ patients treated with mipomersen, apoB and LDL-C were reduced by 20\% with $200 \mathrm{mg} /$ week dose and by more than $30 \%$ with $300 \mathrm{mg} /$ week dose (Akdim et al. 2010b), with the most common adverse effect being injection site erythema (97\%). In the same study, four patients treated with mipomersen (three of which in the highest dose group) experienced transaminase elevations $>3 \times$ ULN with signs of hepatic steatosis (Akdim et al. 2010b). Due to the long half-life of mipomersen, LDL-C levels remain lower than baseline for as long as 2-3 months after the last injection (Akdim et al. 2010b). Similar results have been reported in $\mathrm{HeFH}$ patients with CAD (Stein et al. 2012a). Mipomersen is also effective in HoFH patients, with a $24.7 \%$ mean LDL-C reduction from baseline observed on top of their maximal tolerated lipid-lowering therapy, associated with an overall improvement of plasma lipid profile (Raal et al. 2010). Also in these patients, the most common adverse event was injection site reactions, followed by ALT elevations $\geq 3$ times ULN which occurred in four mipomersen patients and one patient showing also a significant increase in hepatic fat content (Raal et al. 2010).

A 2-year interim report of a long-term trial showed that mipomersen provides sustained reduction in apoB and LDL-C levels. Of note the median liver fat increased during initial 6-12 months, but returned to baseline with longer treatment, suggesting that a liver metabolic adaptation might occur (Santos et al. 2015). Longterm treatment with mipomersen not only reduces LDL-C and other atherogenic lipoprotein levels but may also reduce the incidence of $\mathrm{CV}$ events in patients with FH (Duell et al. 2016).

\section{$4 \quad$ Cholesterol-Lowering Drugs Under Clinical Development}

\subsection{Inclisiran}

Small interfering RNA (siRNA) induces the degradation of a specific mRNA which halts protein synthesis (Norata et al. 2013b). Inclisiran is a specific siRNA which targets PCSK9 mRNA and blocks intracellular PCSK9 synthesis in the liver, as opposed to monoclonal antibodies against PCSK9 which block circulating protein (Fig. 1).

Preclinical studies have shown that a siRNA targeting PCSK9 (ALN-PCS) was effective in reducing plasma PCSK9 and LDL-C levels (Frank-Kamenetsky et al. 2008), and in healthy volunteers, a single intravenous dose of ALN-PCS showed a mean $70 \%$ reduction in circulating PCSK9 plasma levels and a $40 \%$ reduction in LDL-C levels (Fitzgerald et al. 2014).

Inclisiran (ALN-PCSsc) is a siRNA against PCSK9 conjugated to triantennary $\mathrm{N}$-acetylgalactosamine carbohydrate structure allowing the compound to be recognized by the hepatic asialoglycoprotein receptors, which is selectively expressed in hepatocytes, thus resulting in a specific liver uptake. In healthy volunteers, inclisiran induced a dose-dependent reduction of plasma PCSK9 levels (up to $83.8 \%$ ) and LDL-C levels (up to 59.7\%) (Fitzgerald et al. 2017). The ORION clinical program was started to test the efficacy and safety of inclisiran in people with 
atherosclerotic CVD and elevated LDL-C levels despite the maximum tolerated dose of LLT, as well as in patients with FH. In the phase 2 trial ORION-1, conducted in patients at high $\mathrm{CV}$ risk with elevated LDL-C levels treated with the maximum possible dose of a statin with or without additional LLT, individuals received a single dose or two doses (at days 1 and 90) of inclisiran or placebo (Ray et al. 2017). Inclisiran dose-dependently reduced PCSK9 and LDL-C levels (Ray et al. 2017). At day 240, both PCSK9 and LDL-C were significantly lower than at baseline in all inclisiran regimen groups (Ray et al. 2017). The rate of adverse events was similar in inclisiran and placebo groups, and also injection site reactions were rare and similar to those reported with monoclonal antibodies (Ray et al. 2017; Leiter et al. 2019). The treatment with inclisiran every 6 months resulted in durable LDL-C level reductions over 1 year (Ray et al. 2019b). The ORION-3 study is an ongoing open-label extension study of ORION-1 comparing the effect of long-term dosing of inclisiran or evolocumab administration; inclisiran will be administered on day 1 and every 180 days thereafter for up to 4 years (NCT03060577). The interim results showed a favorable safety and tolerability profile for inclisiran, with infrequent, mild, and transient injection site reactions, and no evidence of myalgias or liver or renal adverse events that were related to inclisiran. A robust LDL-C reduction was observed (51\% in all patients), and the time-averaged response showed no loss of effect over 3 years (Kastelein 2019).

The phase 3 trials ORION-9, ORION-10, and ORION-11 were designed to assess the efficacy and safety of inclisiran in HeFH, ASCVD, and/or risk equivalent patients with stable LLT. The ORION-9 showed that LDL-C were reduced by $50 \%$ at day 210, time-averaged percent change of LDL-C days 90-540 was 45\%, and a durable and potent LDL-C-lowering effect was observed over 18 months, independent of the $\mathrm{FH}$ genotype; the rate of adverse events was comparable among groups (Raal et al. 2020). Similar effects were reported in the ORION-10 and ORION-11 trials, with prespecified exploratory analysis on CV events showing a lower rate in patients treated with inclisiran compared to placebo (Ray et al. 2020). Inclisiran has been also tested in four HoFH patients in the ORION-2 pilot study, showing a persistent PCSK9-lowering effect independent of the specific mutation and an LDL-C-lowering effect related to the severity of mutation (maximum -43\%) (Raal 2019). The ORION-5 trial (NCT03851705) is evaluating the effect of placebo or inclisiran in $45 \mathrm{HoFH}$ patients in a 6-month double-blind period, and then all patients will receive inclisiran during an 18-month open-label follow-up period; the study is expected to end June 2021.

The ongoing ORION-4 aims to assess whether PCSK9 inhibition by inclisiran $300 \mathrm{mg}$ safely lowers the risk of major atherosclerotic cardiovascular events in $\geq 15,000$ patients with pre-existing ASCVD during a median treatment duration of 5 years (NCT03705234). Estimated primary completion date is December 2024. 


\subsection{Bempedoic Acid}

Bempedoic acid is a new drug that inhibits the synthesis of cholesterol by inhibiting the activity of ATP citrate lyase (ACLY), the enzyme catalyzing the transformation of citric acid into oxaloacetate and acetyl-CoA (Fig. 4). The inhibition of ACLY, by blocking cholesterol biosynthesis, results in an increased hepatic expression of the LDL receptor (Pinkosky et al. 2016) and a consequent reduction in the circulating levels of LDL-C. Based on these observations, targeting ACLY activity appears to be a promising approach to lower LDL-C levels. A recent Mendelian randomization study, comparing variants in ACLY gene (mimicking the effect of bempedoic acid) with variants in HMGCR gene (mimicking the effect of statins), seems to suggest that inhibiting ACLY translates into cardiovascular protection (Ference et al. 2019b); in fact, the reduction of the risk of major cardiovascular events for each decrease of $10 \mathrm{mg} / \mathrm{dL}$ in LDL-C levels was similar for genetic variants that mimic bempedoic acid or statin activity (Ference et al. 2019b).

Bempedoic acid is a pro-drug, which is converted into its active form by a hepatic enzyme not expressed in skeletal muscle (very-long-chain acyl-CoA sinthetase-1, ACSVL1), which should reduce the potential risk of muscle-related adverse events and may thus represent an important approach in patients intolerant to statins.

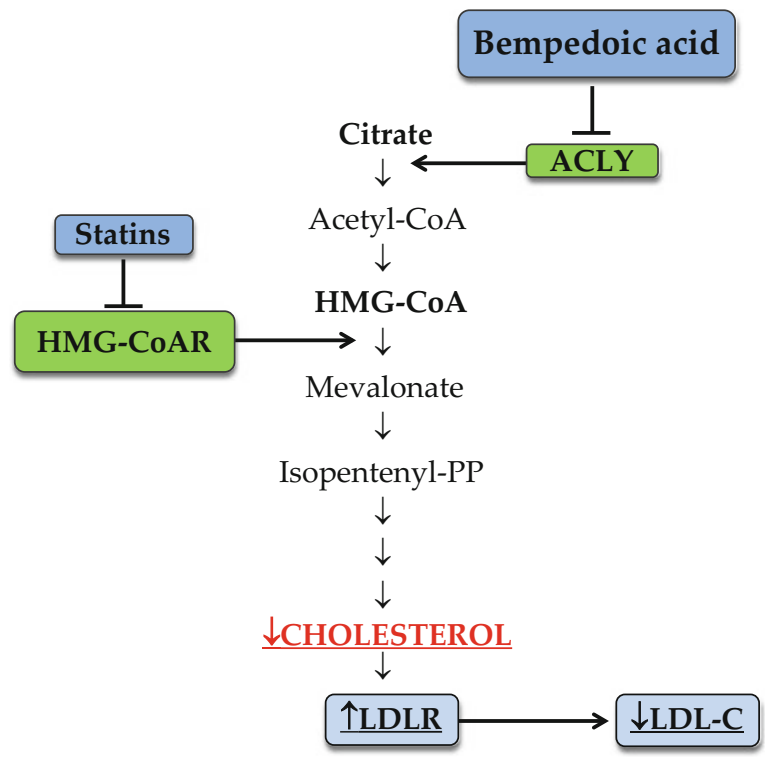

Fig. 4 Mechanism of action of bempedoic acid. Bempedoic acid inhibits cellular cholesterol biosynthesis by blocking the activity of ATP citrate lyase (ACLY), an enzyme upstream of hydroxymethylglutaryl-CoA reductase (the target of statins). Therefore cells upregulate the expression of the LDLR to compensate for reduced cholesterol biosynthesis. A specific enzyme, ACSVL1 (very-long-chain acyl-CoA sinthetase-1), expressed in the liver but not in other peripheral tissues, converts bempedoic acid into the active form thus conferring hepatoselectivity to the drug 
Bempedoic acid was also reported to activate the AMP-activated protein kinase (AMPK) subunit beta1 (Pinkosky et al. 2013), however this subunit appears to be less relevant in humans, and therefore whether bempedoic acid positively impact carbohydrate metabolism in humans remains to be demonstrated.

Bempedoic acid dose-dependently lowered LDL-C levels up to $27 \%$ in hypercholesterolemic patients, independent on their TG levels (Ballantyne et al. 2013). Non-HDL-C and apoB levels and LDL particle number were also significantly reduced (Ballantyne et al. 2013). Hypercholesterolemic patients with type 2 diabetes showed an even greater LDL-C reduction following the treatment with bempedoic acid $(-43 \%)$ (Gutierrez et al. 2014). The treatment with bempedoic acid did not result in a worsening of glycemic control, which is another relevant concern associated with statin therapy (Gutierrez et al. 2014). Two studies have specifically evaluated the effect of bempedoic acid in hypercholesterolemic patients intolerant to statins. One study reported a 32\% LDL-C level reduction after 8 weeks of treatment (vs a $-3.3 \%$ with placebo), with an incidence of muscle-related adverse events similar in the two groups (Thompson et al. 2015). In another study, bempedoic acid alone reduced LDL-C levels up to $30 \%$, compared with a $21 \%$ reduction observed with ezetimibe; the greatest reduction was observed in patients treated with the combination bempedoic acid+ezetimibe that also improved the levels of other lipids (43-48\%) (Thompson et al. 2016). These reductions were similar in statin-tolerant and statin-intolerant patients, and frequencies of muscle-related adverse events were low in all treatment groups (Thompson et al. 2016).

In patients with persistently elevated LDL-C despite a background statin therapy, bempedoic acid induced a significant LDL-C reduction compared with placebo (17\%-24\% vs 4\%), but muscle-related adverse events had similar frequencies in all groups (Ballantyne et al. 2016). Similar results were obtained in patients treated with bempedoic acid added to high-dose atorvastatin background therapy, who showed a $22 \%$ LDL-C level reduction compared with placebo and an overall improved lipid profile (Lalwani et al. 2019). In this study, the addition of bempedoic acid to atorvastatin background therapy resulted in an increased exposure $(<30 \%)$ to atorvastatin, which is suggestive of a weak interaction between the two drugs likely without clinical relevance (Lalwani et al. 2019). The results of these studies suggest that bempedoic acid, alone or in combination with ezetimibe, may represent a valuable approach for the treatment of hypercholesterolemic patients, including those intolerant to statins.

The phase 3 CLEAR program (Cholesterol Lowering via Bempedoic Acid, an ACL-Inhibiting Regimen) includes five studies, four of which have been completed. The CLEAR Harmony and the CLEAR Wisdom studies showed 12.6 and $17.4 \%$ LDL-C level reductions in patients with high LDL-C despite receiving maximum tolerated LLT; both studies showed similar incidence of adverse events (Goldberg et al. 2019; Ray et al. 2019a). The CLEAR Serenity study evaluated the effect of bempedoic acid or placebo in patients with a history of intolerance to at least two statins, showing a significant reduction in LDL-C levels $(-23.6 \%$ vs $-1.3 \%$ with placebo) and other lipid parameters, with similar incidence of adverse events in the treatment groups (Laufs et al. 2019). Similar results were obtained in the CLEAR 
Tranquility trial, which showed that bempedoic acid in combination with ezetimibe further reduced LDL-C levels compared with ezetimibe alone $(28.5 \%)$ in statinintolerant patients, with safety profiles comparable between treatment groups (Ballantyne et al. 2018). An ongoing study (CLEAR Cardiovascular Outcomes) is evaluating whether treatment with bempedoic acid treatment reduces the risk of cardiovascular events in patients at high cardiovascular risk with statin intolerance. The results of this study are expected for 2022 .

\section{$5 \quad$ The Future of Cholesterol Lowering}

\subsection{ANGPTL3- $\mathrm{L}_{\mathrm{Rx}}$}

Angiopoietin-like 3 (ANGPTL3) is an endogenous inhibitor of LPL and endothelial lipase (EL), two enzymes playing an important role in lipoprotein metabolism (Tikka and Jauhiainen 2016). Individuals carrying LOF mutations in the ANGPTL3 gene have lower levels of TG and LDL-C and a significantly reduced CV risk (Dewey et al. 2017; Stitziel et al. 2017; Tarugi et al. 2019). In agreement with this observation, the analysis of plasma levels of ANGPTL3 showed that subjects in the lowest ANGPTL3 level tertile have a significantly reduced risk of myocardial infarction compared to subjects with levels in the highest tertile (Dewey et al. 2017; Stitziel et al. 2017). Based on these observations, ANGPTL3 has been suggested as a possible pharmacological target for the treatment of mixed hyperlipidemias, and for FH patients, due to its cholesterol-lowering effect which is independent of LDLR (Wang et al. 2015). Two different strategies are under investigation to inhibit ANGPTL3: a monoclonal antibody (evinacumab) and an antisense oligonucleotide (ASO, ANGPTL3-L Rx $_{\text {) }}$ (Fig. 5), both reducing plasma LDL-C and TG levels.

Evinacumab is a fully human monoclonal antibody targeting ANGPTL3 able to reduce LDL-C (up to 23\%) and TG (up to 76\%) levels in healthy volunteers (Dewey et al. 2017). When tested in HoFH patients, including two null homozygotes and one compound heterozygote with two null alleles, evinacumab added to ongoing LLT further reduced LDL-C levels by 49\% (Gaudet et al. 2017). Recently, a phase 3 trial confirmed that evinacumab halves LDL-C levels in $\mathrm{HoFH}$ patients independent of the causative mutation, with $47 \%$ of patients achieving LDL-C levels $<100 \mathrm{mg} / \mathrm{dL}$ (http://www.prnewswire.com/news-releases/regeneron-announces-positive-toplineresults-from-phase-3-trial-of-evinacumab-in-patients-with-severe-inherited-formof-high-cholesterol-300901035.html). Ongoing studies are assessing, alongside the lipid-lowering effect, the safety and long-term tolerability (up to 192 weeks) of evinacumab therapy in $\mathrm{HoFH}$ patients and the potential development of anti-drug antibodies. Evinacumab is also tested in patients with $\mathrm{HeFH}$ or non-FH but with a history of atherosclerotic cardiovascular disease with LDL-C levels persistently elevated despite receiving maximally tolerated LLT.

ANGPTL3- $\mathrm{L}_{\mathrm{Rx}}$ is an antisense oligonucleotide containing three GalNac residues to promote the specific recognition by hepatic ASGPR1 receptors (Graham et al. 2017). In preclinical studies, the treatment with ANGPTL3-L $\mathrm{Rx}_{\mathrm{Rx}}$ significantly 


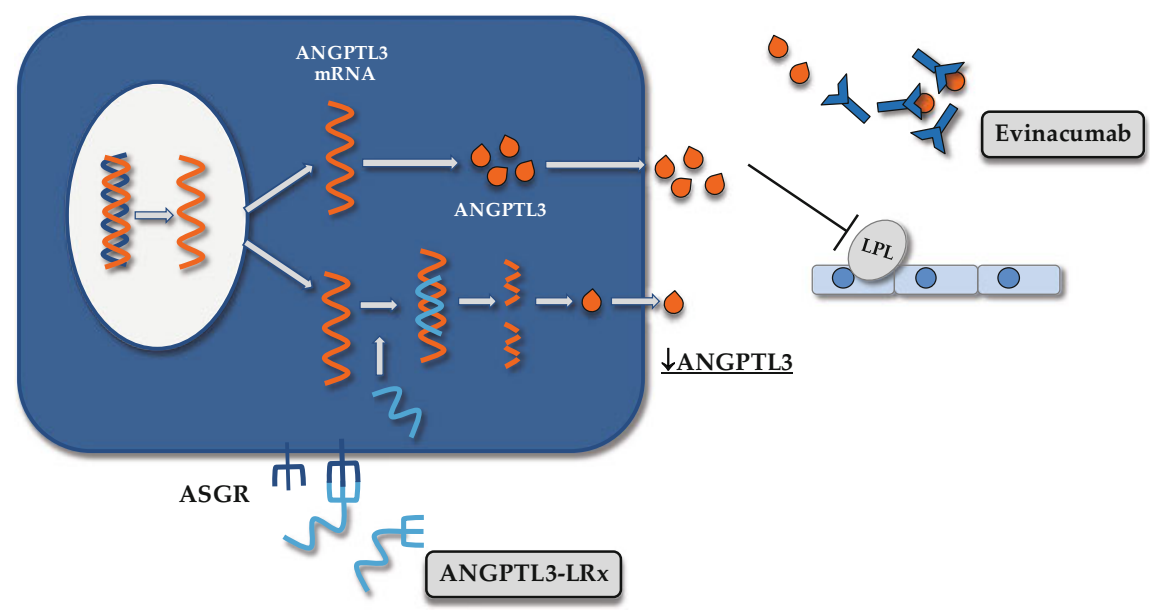

Fig. 5 Mechanism of action of antisense oligonucleotides. ANGPTL3-Lrx and APOA(a)-Lrx are antisense oligonucleotides containing three GalNac residues which promote the specific recognition by hepatic ASGPR receptors. Once internalized, they inhibit protein synthesis of ANGPTL3 or apo (a), respectively, by binding the corresponding mRNAs and inducing their degradation

reduced ANGPTL3 protein levels, which translated into a reduction of plasma TG and LDL-C, hepatic TG content, progression of atherosclerosis, and improvement of insulin sensitivity (Graham et al. 2017). In healthy subjects with elevated TG levels, ANGPTL3- $\mathrm{L}_{\mathrm{Rx}}$ produced a dose-dependent reduction in circulating levels of ANGPTL3 (47-84\%), TG (33-63\%), LDL-C (1.3-33\%), VLDL-C (28-60\%), and apoCIII (19-59\%) (Graham et al. 2017). No serious adverse events were reported during treatment, and no evidence of pro-thrombotic effects, bleeding episodes, and reduction of platelet count was reported compared to ASOs of previous generations (Graham et al. 2017).

\section{Conclusions}

In the last decade, several novel therapeutic approaches have been tested and some approved for reducing plasma lipids and lipoproteins. Some drugs are already available in clinical practice; others are at late stages of development. From a pharmacological perspective, in addition to statins, bempedoic acid was shown to produce an effective inhibition of cholesterol biosynthesis in the liver, while other molecules inhibit cholesterol absorption in the intestine (ezetimibe), inhibit lipoproteins synthesis in the liver and the intestine (lomitapide), or promote lipoprotein catabolism (PCSK9 inhibitors or ANGPTL3 inhibitors). Interest is also emerging on the possibility to target $\mathrm{Lp}(\mathrm{a})$. 
The new technology of antisense oligonucleotides and small interfering RNAs has clearly opened a fast track for drugs targeting pathways likely to be causal to CVD. The availability of these approaches will definitely improve the management of dyslipidemias, particularly hypercholesterolemias.

\section{References}

Ahn CH, Choi SH (2015) New drugs for treating dyslipidemia: beyond statins. Diabetes Metab J 39:87-94. https://doi.org/10.4093/dmj.2015.39.2.87

Akdim F, Stroes ES, Sijbrands EJ et al (2010a) Efficacy and safety of mipomersen, an antisense inhibitor of apolipoprotein $\mathrm{B}$, in hypercholesterolemic subjects receiving stable statin therapy. $\mathrm{J}$ Am Coll Cardiol 55:1611-1618. https://doi.org/10.1016/j.jacc.2009.11.069

Akdim F, Visser ME, Tribble DL et al (2010b) Effect of mipomersen, an apolipoprotein B synthesis inhibitor, on low-density lipoprotein cholesterol in patients with familial hypercholesterolemia. Am J Cardiol 105:1413-1419. https://doi.org/10.1016/j.amjcard.2010.01.003

Akdim F, Tribble DL, Flaim JD et al (2011) Efficacy of apolipoprotein B synthesis inhibition in subjects with mild-to-moderate hyperlipidaemia. Eur Heart J 32:2650-2659. https://doi.org/10. 1093/eurheartj/ehr148

Baigent C, Keech A, Kearney PM et al (2005) Efficacy and safety of cholesterol-lowering treatment: prospective meta-analysis of data from 90,056 participants in 14 randomised trials of statins. Lancet 366:1267-1278. https://doi.org/10.1016/S0140-6736(05)67394-1

Baigent C, Blackwell L, Emberson J et al (2010) Efficacy and safety of more intensive lowering of LDL cholesterol: a meta-analysis of data from 170,000 participants in 26 randomised trials. Lancet 376:1670-1681. https://doi.org/10.1016/S0140-6736(10)61350-5

Baigent C, Landray MJ, Reith C et al (2011) The effects of lowering LDL cholesterol with simvastatin plus ezetimibe in patients with chronic kidney disease (study of heart and renal protection): a randomised placebo-controlled trial. Lancet 377:2181-2192. https://doi.org/10. 1016/S0140-6736(11)60739-3

Ballantyne CM, Davidson MH, Macdougall DE et al (2013) Efficacy and safety of a novel dual modulator of adenosine triphosphate-citrate lyase and adenosine monophosphate-activated protein kinase in patients with hypercholesterolemia: results of a multicenter, randomized, double-blind, placebo-controlled, parallel-group trial. J Am Coll Cardiol 62:1154-1162. https://doi.org/10.1016/j.jacc.2013.05.050

Ballantyne CM, McKenney JM, MacDougall DE, Margulies JR, Robinson PL, Hanselman JC, Lalwani ND (2016) Effect of ETC-1002 on serum low-density lipoprotein cholesterol in hypercholesterolemic patients receiving statin therapy. Am J Cardiol 117:1928-1933. https:// doi.org/10.1016/j.amjcard.2016.03.043

Ballantyne CM, Banach M, Mancini GBJ, Lepor NE, Hanselman JC, Zhao X, Leiter LA (2018) Efficacy and safety of bempedoic acid added to ezetimibe in statin-intolerant patients with hypercholesterolemia: a randomized, placebo-controlled study. Atherosclerosis 277:195-203. https://doi.org/10.1016/j.atherosclerosis.2018.06.002

Banach M, Rizzo M, Toth PP et al (2015) Statin intolerance - an attempt at a unified definition. Position paper from an International Lipid Expert Panel. Expert Opin Drug Saf 14:935-955. https://doi.org/10.1517/14740338.2015.1039980

Bays H, Gaudet D, Weiss R et al (2015) Alirocumab as add-on to atorvastatin versus other lipid treatment strategies: ODYSSEY OPTIONS I randomized trial. J Clin Endocrinol Metab 100:3140-3148. https://doi.org/10.1210/jc.2015-1520

Benn M, Nordestgaard BG, Grande P, Schnohr P, Tybjaerg-Hansen A (2010) PCSK9 R46L, low-density lipoprotein cholesterol levels, and risk of ischemic heart disease: 3 independent studies and meta-analyses. J Am Coll Cardiol 55:2833-2842. https://doi.org/10.1016/j.jacc. 2010.02.044 
Berberich AJ, Hegele RA (2017) Lomitapide for the treatment of hypercholesterolemia. Expert Opin Pharmacother 18:1261-1268. https://doi.org/10.1080/14656566.2017.1340941

Blom DJ, Hala T, Bolognese M et al (2014) A 52-week placebo-controlled trial of evolocumab in hyperlipidemia. N Engl J Med 370:1809-1819. https://doi.org/10.1056/NEJMoa1316222

Blom DJ, Fayad ZA, Kastelein JJ et al (2016) LOWER, a registry of lomitapide-treated patients with homozygous familial hypercholesterolemia: rationale and design. J Clin Lipidol 10:273-282. https://doi.org/10.1016/j.jacl.2015.11.011

Bonaca MP, Nault P, Giugliano RP et al (2018) Low-density lipoprotein cholesterol lowering with evolocumab and outcomes in patients with peripheral artery disease: insights from the FOURIER trial (further cardiovascular outcomes research with PCSK9 inhibition in subjects with elevated risk). Circulation 137:338-350. https://doi.org/10.1161/CIRCULATIONAHA. 117.032235

Brown MS, Goldstein JL (1986) A receptor-mediated pathway for cholesterol homeostasis. Science 232:34-47

Cannon CP, Blazing MA, Giugliano RP et al (2015a) Ezetimibe added to statin therapy after acute coronary syndromes. N Engl J Med 372:2387-2397. https://doi.org/10.1056/NEJMoa1410489

Cannon CP, Cariou B, Blom D et al (2015b) Efficacy and safety of alirocumab in high cardiovascular risk patients with inadequately controlled hypercholesterolaemia on maximally tolerated doses of statins: the ODYSSEY COMBO II randomized controlled trial. Eur Heart J 36:1186-1194. https://doi.org/10.1093/eurheartj/ehv028

Catapano A, Brady WE, King TR, Palmisano J (2005) Lipid altering-efficacy of ezetimibe co-administered with simvastatin compared with rosuvastatin: a meta-analysis of pooled data from 14 clinical trials. Curr Med Res Opin 21:1123-1130. https://doi.org/10.1185/ $030079905 \times 50642$

Catapano AL, Davidson MH, Ballantyne CM, Brady WE, Gazzara RA, Tomassini JE, Tershakovec AM (2006) Lipid-altering efficacy of the ezetimibe/simvastatin single tablet versus rosuvastatin in hypercholesterolemic patients. Curr Med Res Opin 22:2041-2053. https://doi.org/10.1185/ 030079906X132721

Chan DK, O'Rourke F, Shen Q, Mak JC, Hung WT (2011) Meta-analysis of the cardiovascular benefits of intensive lipid lowering with statins. Acta Neurol Scand 124:188-195. https://doi. org/10.1111/j.1600-0404.2010.01450.x

Chatzizisis YS, Koskinas KC, Misirli G, Vaklavas C, Hatzitolios A, Giannoglou GD (2010) Risk factors and drug interactions predisposing to statin-induced myopathy: implications for risk assessment, prevention and treatment. Drug Saf 33:171-187. https://doi.org/10.2165/ 11319380-000000000-00000

Cohen J, Pertsemlidis A, Kotowski IK, Graham R, Garcia CK, Hobbs HH (2005) Low LDL cholesterol in individuals of African descent resulting from frequent nonsense mutations in PCSK9. Nat Genet 37:161-165. https://doi.org/10.1038/ng1509

Cohen JC, Boerwinkle E, Mosley TH Jr, Hobbs HH (2006) Sequence variations in PCSK9, low LDL, and protection against coronary heart disease. N Engl J Med 354:1264-1272. https://doi. org/10.1056/NEJMoa054013

Crooke ST, Geary RS (2013) Clinical pharmacological properties of mipomersen (Kynamro), a second generation antisense inhibitor of apolipoprotein B. Br J Clin Pharmacol 76:269-276. https://doi.org/10.1111/j.1365-2125.2012.04469.x

Cuchel M, Bloedon LT, Szapary PO et al (2007) Inhibition of microsomal triglyceride transfer protein in familial hypercholesterolemia. N Engl J Med 356:148-156. https://doi.org/10.1056/ NEJMoa061189

Cuchel M, Meagher EA, du Toit TH et al (2013) Efficacy and safety of a microsomal triglyceride transfer protein inhibitor in patients with homozygous familial hypercholesterolaemia: a singlearm, open-label, phase 3 study. Lancet 381:40-46. https://doi.org/10.1016/S0140-6736(12) 61731-0

Cuchel M, Bruckert E, Ginsberg HN et al (2014) Homozygous familial hypercholesterolaemia: new insights and guidance for clinicians to improve detection and clinical management. A position 
paper from the Consensus Panel on Familial Hypercholesterolaemia of the European Atherosclerosis Society. Eur Heart J 35:2146-2157. https://doi.org/10.1093/eurheartj/ehu274

Da Dalt L, Ruscica M, Bonacina F et al (2019) PCSK9 deficiency reduces insulin secretion and promotes glucose intolerance: the role of the low-density lipoprotein receptor. Eur Heart $\mathbf{J}$ 40:357-368. https://doi.org/10.1093/eurheartj/ehy357

Davis HR, Veltri EP (2007) Zetia: inhibition of Niemann-pick C1 like 1 (NPC1L1) to reduce intestinal cholesterol absorption and treat hyperlipidemia. J Atheroscler Thromb 14:99-108. https://doi.org/10.5551/jat.14.99

Descamps OS, De Sutter J, Guillaume M, Missault L (2011) Where does the interplay between cholesterol absorption and synthesis in the context of statin and/or ezetimibe treatment stand today? Atherosclerosis 217:308-321. https://doi.org/10.1016/j.atherosclerosis.2011.06.010

Dewey FE, Gusarova V, Dunbar RL et al (2017) Genetic and pharmacologic inactivation of ANGPTL3 and cardiovascular disease. N Engl J Med 377:211-221. https:/doi.org/10.1056/ NEJMoa1612790

Duell PB, Santos RD, Kirwan BA, Witztum JL, Tsimikas S, Kastelein JJ (2016) Long-term mipomersen treatment is associated with a reduction in cardiovascular events in patients with familial hypercholesterolemia. J Clin Lipidol 10:1011-1021. https://doi.org/10.1016/j.jacl. 2016.04.013

Dufour R, Bergeron J, Gaudet D et al (2017) Open-label therapy with alirocumab in patients with heterozygous familial hypercholesterolemia: results from three years of treatment. Int J Cardiol 228:754-760. https://doi.org/10.1016/j.ijcard.2016.11.046

Farnier M, Jones P, Severance R et al (2016) Efficacy and safety of adding alirocumab to rosuvastatin versus adding ezetimibe or doubling the rosuvastatin dose in high cardiovascularrisk patients: the ODYSSEY OPTIONS II randomized trial. Atherosclerosis 244:138-146. https://doi.org/10.1016/j.atherosclerosis.2015.11.010

Farnier M, Hovingh GK, Langslet G et al (2018) Long-term safety and efficacy of alirocumab in patients with heterozygous familial hypercholesterolemia: an open-label extension of the ODYSSEY program. Atherosclerosis 278:307-314. https://doi.org/10.1016/j.atherosclerosis. 2018.08.036

Ference BA, Robinson JG, Brook RD et al (2016) Variation in PCSK9 and HMGCR and risk of cardiovascular disease and diabetes. N Engl J Med 375:2144-2153. https://doi.org/10.1056/ NEJMoa1604304

Ference BA, Ginsberg HN, Graham I et al (2017) Low-density lipoproteins cause atherosclerotic cardiovascular disease. 1. Evidence from genetic, epidemiologic, and clinical studies. A consensus statement from the European Atherosclerosis Society Consensus Panel. Eur Heart J 38:2459-2472. https://doi.org/10.1093/eurheartj/ehx144

Ference BA, Kastelein JJP, Ray KK et al (2019a) Association of triglyceride-lowering LPL variants and LDL-C-lowering LDLR variants with risk of coronary heart disease. JAMA 321:364-373. https://doi.org/10.1001/jama.2018.20045

Ference BA, Ray KK, Catapano AL et al (2019b) Mendelian randomization study of ACLY and cardiovascular disease. N Engl J Med 380:1033-1042. https://doi.org/10.1056/ NEJMoa1806747

Fitzgerald K, Frank-Kamenetsky M, Shulga-Morskaya S et al (2014) Effect of an RNA interference drug on the synthesis of proprotein convertase subtilisin/kexin type 9 (PCSK9) and the concentration of serum LDL cholesterol in healthy volunteers: a randomised, single-blind, placebo-controlled, phase 1 trial. Lancet 383:60-68. https://doi.org/10.1016/S0140-6736(13) 61914-5

Fitzgerald K, White S, Borodovsky A et al (2017) A highly durable RNAi therapeutic inhibitor of PCSK9. N Engl J Med 376:41-51. https://doi.org/10.1056/NEJMoa1609243

Fogacci F, Ferri N, Toth PP, Ruscica M, Corsini A, Cicero AFG (2019) Efficacy and safety of mipomersen: a systematic review and meta-analysis of randomized clinical trials. Drugs 79:751-766. https://doi.org/10.1007/s40265-019-01114-z 
Foody JM, Toth PP, Tomassini JE et al (2013) Changes in LDL-C levels and goal attainment associated with addition of ezetimibe to simvastatin, atorvastatin, or rosuvastatin compared with titrating statin monotherapy. Vasc Health Risk Manag 9:719-727. https://doi.org/10.2147/ VHRM.S49840

Frank-Kamenetsky M, Grefhorst A, Anderson NN et al (2008) Therapeutic RNAi targeting PCSK9 acutely lowers plasma cholesterol in rodents and LDL cholesterol in nonhuman primates. Proc Natl Acad Sci U S A 105:11915-11920. https://doi.org/10.1073/pnas.0805434105

Fruchart JC, Davignon J, Hermans MP et al (2014) Residual macrovascular risk in 2013: what have we learned? Cardiovasc Diabetol 13:26. https://doi.org/10.1186/1475-2840-13-26

Gagne C, Gaudet D, Bruckert E (2002) Efficacy and safety of ezetimibe coadministered with atorvastatin or simvastatin in patients with homozygous familial hypercholesterolemia. Circulation 105:2469-2475

Gaudet D, Gipe DA, Pordy R et al (2017) ANGPTL3 inhibition in homozygous familial hypercholesterolemia. N Engl J Med 377:296-297. https://doi.org/10.1056/NEJMc1705994

Giugliano RP, Desai NR, Kohli P et al (2012) Efficacy, safety, and tolerability of a monoclonal antibody to proprotein convertase subtilisin/kexin type 9 in combination with a statin in patients with hypercholesterolaemia (LAPLACE-TIMI 57): a randomised, placebo-controlled, doseranging, phase 2 study. Lancet 380:2007-2017. https://doi.org/10.1016/S0140-6736(12) 61770-X

Giugliano RP, Mach F, Zavitz K et al (2017a) Cognitive function in a randomized trial of evolocumab. N Engl J Med 377:633-643. https://doi.org/10.1056/NEJMoa1701131

Giugliano RP, Pedersen TR, Park JG et al (2017b) Clinical efficacy and safety of achieving very low LDL-cholesterol concentrations with the PCSK9 inhibitor evolocumab: a prespecified secondary analysis of the FOURIER trial. Lancet 390:1962-1971. https://doi.org/10.1016/ S0140-6736(17)32290-0

Giugliano RP, Cannon CP, Blazing MA et al (2018) Benefit of adding ezetimibe to statin therapy on cardiovascular outcomes and safety in patients with versus without diabetes mellitus: results from IMPROVE-IT (improved reduction of outcomes: vytorin efficacy international trial). Circulation 137:1571-1582. https://doi.org/10.1161/CIRCULATIONAHA.117.030950

Glueck CJ, Kelley W, Gupta A, Fontaine RN, Wang P, Gartside PS (1997) Prospective 10-year evaluation of hypobetalipoproteinemia in a cohort of 772 firefighters and cross-sectional evaluation of hypocholesterolemia in 1,479 men in the National Health and Nutrition Examination Survey I. Metabolism 46:625-633

Goldberg AC, Leiter LA, Stroes ESG et al (2019) Effect of bempedoic acid vs placebo added to maximally tolerated statins on low-density lipoprotein cholesterol in patients at high risk for cardiovascular disease: the CLEAR wisdom randomized clinical trial. JAMA 322:1780-1788. https://doi.org/10.1001/jama.2019.16585

Graham MJ, Lee RG, Brandt TA et al (2017) Cardiovascular and metabolic effects of ANGPTL3 antisense oligonucleotides. N Engl J Med 377:222-232. https://doi.org/10.1056/ NEJMoa1701329

Gutierrez MJ, Rosenberg NL, Macdougall DE et al (2014) Efficacy and safety of ETC-1002, a novel investigational low-density lipoprotein-cholesterol-lowering therapy for the treatment of patients with hypercholesterolemia and type 2 diabetes mellitus. Arterioscler Thromb Vasc Biol 34:676-683. https://doi.org/10.1161/ATVBAHA.113.302677

Hashemi N, Odze RD, McGowan MP, Santos RD, Stroes ES, Cohen DE (2014) Liver histology during Mipomersen therapy for severe hypercholesterolemia. J Clin Lipidol 8:606-611. https:// doi.org/10.1016/j.jacl.2014.08.002

Hooper AJ, Burnett JR, Watts GF (2015) Contemporary aspects of the biology and therapeutic regulation of the microsomal triglyceride transfer protein. Circ Res 116:193-205. https://doi. org/10.1161/CIRCRESAHA.116.304637

Hopkins PN, Defesche J, Fouchier SW et al (2015) Characterization of autosomal dominant hypercholesterolemia caused by PCSK9 gain of function mutations and its specific treatment 
with alirocumab, a PCSK9 monoclonal antibody. Circ Cardiovasc Genet 8:823-831. https://doi. org/10.1161/CIRCGENETICS.115.001129

Hovingh GK, Davidson MH, Kastelein JJ, O'Connor AM (2013) Diagnosis and treatment of familial hypercholesterolaemia. Eur Heart J 34:962-971. https://doi.org/10.1093/eurheartj/ eht015

Kastelein JJP (2019) ORION-3. Presented at National Lipid Association (NLA) Scientific Sessions, Miami, May 2019

Kastelein JJ, Wedel MK, Baker BF et al (2006) Potent reduction of apolipoprotein B and low-density lipoprotein cholesterol by short-term administration of an antisense inhibitor of apolipoprotein B. Circulation 114:1729-1735. https://doi.org/10.1161/CIRCULATIONAHA. 105.606442

Kastelein JJ, Akdim F, Stroes ES et al (2008) Simvastatin with or without ezetimibe in familial hypercholesterolemia. N Engl J Med 358:1431-1443. https://doi.org/10.1056/NEJMoa0800742

Kastelein JJ, Robinson JG, Farnier M et al (2014) Efficacy and safety of alirocumab in patients with heterozygous familial hypercholesterolemia not adequately controlled with current lipidlowering therapy: design and rationale of the ODYSSEY FH studies. Cardiovasc Drugs Ther 28:281-289. https://doi.org/10.1007/s10557-014-6523-Z

Kastelein JJ, Ginsberg HN, Langslet G et al (2015) ODYSSEY FH I and FH II: 78 week results with alirocumab treatment in 735 patients with heterozygous familial hypercholesterolaemia. Eur Heart J 36:2996-3003. https://doi.org/10.1093/eurheartj/ehv370

Kathiresan S (2008) A PCSK9 missense variant associated with a reduced risk of early-onset myocardial infarction. N Engl J Med 358:2299-2300. https://doi.org/10.1056/NEJMc0707445

Kent ST, Rosenson RS, Avery CL et al (2017) PCSK9 loss-of-function variants, low-density lipoprotein cholesterol, and risk of coronary heart disease and stroke: data from 9 studies of blacks and whites. Circ Cardiovasc Genet 10:e001632. https://doi.org/10.1161/ CIRCGENETICS.116.001632

Kereiakes DJ, Robinson JG, Cannon CP, Lorenzato C, Pordy R, Chaudhari U, Colhoun HM (2015) Efficacy and safety of the proprotein convertase subtilisin/kexin type 9 inhibitor alirocumab among high cardiovascular risk patients on maximally tolerated statin therapy: the ODYSSEY COMBO I study. Am Heart J 169:906-915. https://doi.org/10.1016/j.ahj.2015.03.004

Koren MJ, Scott R, Kim JB et al (2012) Efficacy, safety, and tolerability of a monoclonal antibody to proprotein convertase subtilisin/kexin type 9 as monotherapy in patients with hypercholesterolaemia (MENDEL): a randomised, double-blind, placebo-controlled, phase 2 study. Lancet 380:1995-2006. https://doi.org/10.1016/S0140-6736(12)61771-1

Koren MJ, Lundqvist P, Bolognese M et al (2014) Anti-PCSK9 monotherapy for hypercholesterolemia: the MENDEL-2 randomized, controlled phase III clinical trial of evolocumab. J Am Coll Cardiol 63:2531-2540. https://doi.org/10.1016/j.jacc.2014.03.018

Koren MJ, Sabatine MS, Giugliano RP et al (2019) Long-term efficacy and safety of evolocumab in patients with hypercholesterolemia. J Am Coll Cardiol 74:2132-2146. https://doi.org/10.1016/j. jacc.2019.08.1024

Lalwani ND, Hanselman JC, MacDougall DE, Sterling LR, Cramer CT (2019) Complementary low-density lipoprotein-cholesterol lowering and pharmacokinetics of adding bempedoic acid (ETC-1002) to high-dose atorvastatin background therapy in hypercholesterolemic patients: a randomized placebo-controlled trial. J Clin Lipidol 13(4):568-579. https://doi.org/10.1016/j. jacl.2019.05.003

Laufs U, Banach M, Mancini GBJ et al (2019) Efficacy and safety of bempedoic acid in patients with hypercholesterolemia and statin intolerance. J Am Heart Assoc 8:e011662. https://doi.org/ 10.1161/JAHA.118.011662

Leiter LA, Teoh H, Kallend D et al (2019) Inclisiran lowers LDL-C and PCSK9 irrespective of diabetes status: the ORION-1 randomized clinical trial. Diabetes Care 42:173-176. https://doi. org/10.2337/dc18-1491

Leren TP (2014) Sorting an LDL receptor with bound PCSK9 to intracellular degradation. Atherosclerosis 237:76-81. https://doi.org/10.1016/j.atherosclerosis.2014.08.038 
Lorenzi M, Ambegaonkar B, Baxter CA, Jansen J, Zoratti MJ, Davies G (2019) Ezetimibe in highrisk, previously treated statin patients: a systematic review and network meta-analysis of lipid efficacy. Clin Res Cardiol 108:487-509. https://doi.org/10.1007/s00392-018-1379-z

Mach F, Baigent C, Catapano AL et al (2020) 2019 ESC/EAS Guidelines for the management of dyslipidaemias: lipid modification to reduce cardiovascular risk. Eur Heart J 41:111-188. https://doi.org/10.1093/eurheartj/ehz455

McGowan MP, Tardif JC, Ceska R et al (2012) Randomized, placebo-controlled trial of mipomersen in patients with severe hypercholesterolemia receiving maximally tolerated lipidlowering therapy. PLoS One 7:e49006. https://doi.org/10.1371/journal.pone.0049006

McKenney JM, Koren MJ, Kereiakes DJ, Hanotin C, Ferrand AC, Stein EA (2012) Safety and efficacy of a monoclonal antibody to proprotein convertase subtilisin/kexin type 9 serine protease, SAR236553/REGN727, in patients with primary hypercholesterolemia receiving ongoing stable atorvastatin therapy. J Am Coll Cardiol 59:2344-2353. https://doi.org/10. 1016/j.jacc.2012.03.007

Mikhailidis DP, Sibbring GC, Ballantyne CM, Davies GM, Catapano AL (2007) Meta-analysis of the cholesterol-lowering effect of ezetimibe added to ongoing statin therapy. Curr Med Res Opin 23:2009-2026. https://doi.org/10.1185/030079907X210507

Mills EJ, O’Regan C, Eyawo O, Wu P, Mills F, Berwanger O, Briel M (2011a) Intensive statin therapy compared with moderate dosing for prevention of cardiovascular events: a metaanalysis of $>40000$ patients. Eur Heart J 32:1409-1415. https://doi.org/10.1093/eurheartj/ ehr035

Mills EJ, Wu P, Chong G et al (2011b) Efficacy and safety of statin treatment for cardiovascular disease: a network meta-analysis of 170,255 patients from 76 randomized trials. QJM 104:109-124. https://doi.org/10.1093/qjmed/hcq165

Moriarty PM, Thompson PD, Cannon CP et al (2015) Efficacy and safety of alirocumab vs ezetimibe in statin-intolerant patients, with a statin rechallenge arm: the ODYSSEY ALTERNATIVE randomized trial. J Clin Lipidol 9:758-769. https://doi.org/10.1016/j.jacl.2015.08.006

Moriarty PM, Parhofer KG, Babirak SP et al (2016) Alirocumab in patients with heterozygous familial hypercholesterolaemia undergoing lipoprotein apheresis: the ODYSSEY ESCAPE trial. Eur Heart J 37:3588-3595. https://doi.org/10.1093/eurheartj/ehw388

Morrone D, Weintraub WS, Toth PP et al (2012) Lipid-altering efficacy of ezetimibe plus statin and statin monotherapy and identification of factors associated with treatment response: a pooled analysis of over 21,000 subjects from 27 clinical trials. Atherosclerosis 223:251-261. https:// doi.org/10.1016/j.atherosclerosis.2012.02.016

Naci H, Brugts JJ, Fleurence R, Tsoi B, Toor H, Ades AE (2013) Comparative benefits of statins in the primary and secondary prevention of major coronary events and all-cause mortality: a network meta-analysis of placebo-controlled and active-comparator trials. Eur J Prev Cardiol 20:641-657. https://doi.org/10.1177/2047487313480435

Naoumova RP, Tosi I, Patel D et al (2005) Severe hypercholesterolemia in four British families with the D374Y mutation in the PCSK9 gene: long-term follow-up and treatment response. Arterioscler Thromb Vasc Biol 25:2654-2660. https://doi.org/10.1161/01.ATV.0000190668. 94752.ab

Nicholls SJ, Puri R, Anderson T et al (2016) Effect of evolocumab on progression of coronary disease in statin-treated patients: the GLAGOV randomized clinical trial. JAMA 316:2373-2384. https://doi.org/10.1001/jama.2016.16951

Nissen SE, Stroes E, Dent-Acosta RE et al (2016) Efficacy and tolerability of evolocumab vs ezetimibe in patients with muscle-related statin intolerance: the GAUSS-3 randomized clinical trial. JAMA 315:1580-1590. https://doi.org/10.1001/jama.2016.3608

Norata GD, Ballantyne CM, Catapano AL (2013a) New therapeutic principles in dyslipidaemia: focus on LDL and Lp(a) lowering drugs. Eur Heart J 34:1783-1789. https://doi.org/10.1093/ eurheartj/eht088

Norata GD, Tibolla G, Catapano AL (2013b) Gene silencing approaches for the management of dyslipidaemia. Trends Pharmacol Sci 34:198-205. https://doi.org/10.1016/j.tips.2013.01.010 
Norata GD, Tavori H, Pirillo A, Fazio S, Catapano AL (2016) Biology of proprotein convertase subtilisin kexin 9: beyond low-density lipoprotein cholesterol lowering. Cardiovasc Res 112:429-442. https://doi.org/10.1093/cvr/cvw194

Nordestgaard BG, Chapman MJ, Humphries SE et al (2013) Familial hypercholesterolaemia is underdiagnosed and undertreated in the general population: guidance for clinicians to prevent coronary heart disease: consensus statement of the European Atherosclerosis Society. Eur Heart J 34:3478-3490a. https://doi.org/10.1093/eurheartj/eht273

Peloso GM, Nomura A, Khera AV et al (2019) Rare protein-truncating variants in APOB, lower low-density lipoprotein cholesterol, and protection against coronary heart disease. Circ Genom Precis Med 12:e002376. https://doi.org/10.1161/CIRCGEN.118.002376

Perego C, Da Dalt L, Pirillo A, Galli A, Catapano AL, Norata GD (2019) Cholesterol metabolism, pancreatic beta-cell function and diabetes. Biochim Biophys Acta Mol Basis Dis 1865:2149-2156. https://doi.org/10.1016/j.bbadis.2019.04.012

Pinkosky SL, Filippov S, Srivastava RA et al (2013) AMP-activated protein kinase and ATP-citrate lyase are two distinct molecular targets for ETC-1002, a novel small molecule regulator of lipid and carbohydrate metabolism. J Lipid Res 54:134-151. https://doi.org/10.1194/jlr.M030528

Pinkosky SL, Newton RS, Day EA et al (2016) Liver-specific ATP-citrate lyase inhibition by bempedoic acid decreases LDL-C and attenuates atherosclerosis. Nat Commun 7:13457. https:// doi.org/10.1038/ncomms 13457

Pirillo A, Catapano AL (2015) Statin intolerance: diagnosis and remedies. Curr Cardiol Rep 17:27. https://doi.org/10.1007/s11886-015-0582-z

Pisciotta L, Fasano T, Bellocchio A et al (2007) Effect of ezetimibe coadministered with statins in genotype-confirmed heterozygous FH patients. Atherosclerosis 194:e116-e122. https://doi.org/ 10.1016/j.atherosclerosis.2006.10.036

Qiu C, Zeng P, Li X et al (2017) What is the impact of PCSK9 rs505151 and rs11591147 polymorphisms on serum lipids level and cardiovascular risk: a meta-analysis. Lipids Health Dis 16:111. https://doi.org/10.1186/s12944-017-0506-6

Raal FJ (2019) ORION-2. Presented at EAS, Maastricht, May 2019

Raal FJ, Santos RD, Blom DJ et al (2010) Mipomersen, an apolipoprotein B synthesis inhibitor, for lowering of LDL cholesterol concentrations in patients with homozygous familial hypercholesterolaemia: a randomised, double-blind, placebo-controlled trial. Lancet 375:998-1006. https://doi.org/10.1016/S0140-6736(10)60284-X

Raal F, Scott R, Somaratne R, Bridges I, Li G, Wasserman SM, Stein EA (2012) Low-density lipoprotein cholesterol-lowering effects of AMG 145, a monoclonal antibody to proprotein convertase subtilisin/kexin type 9 serine protease in patients with heterozygous familial hypercholesterolemia: the Reduction of LDL-C with PCSK9 Inhibition in Heterozygous Familial Hypercholesterolemia Disorder (RUTHERFORD) randomized trial. Circulation 126:2408-2417. https://doi.org/10.1161/CIRCULATIONAHA.112.144055

Raal FJ, Honarpour N, Blom DJ et al (2015a) Inhibition of PCSK9 with evolocumab in homozygous familial hypercholesterolaemia (TESLA part B): a randomised, double-blind, placebocontrolled trial. Lancet 385:341-350. https://doi.org/10.1016/S0140-6736(14)61374-X

Raal FJ, Stein EA, Dufour R et al (2015b) PCSK9 inhibition with evolocumab (AMG 145) in heterozygous familial hypercholesterolaemia (RUTHERFORD-2): a randomised, double-blind, placebo-controlled trial. Lancet 385:331-340. https://doi.org/10.1016/S0140-6736(14)61399-4

Raal FJ, Hovingh GK, Blom D et al (2017) Long-term treatment with evolocumab added to conventional drug therapy, with or without apheresis, in patients with homozygous familial hypercholesterolaemia: an interim subset analysis of the open-label TAUSSIG study. Lancet Diabetes Endocrinol 5:280-290. https://doi.org/10.1016/S2213-8587(17)30044-X

Raal FJ, Kallend D, Ray KK et al (2020) Inclisiran for the treatment of heterozygous familial hypercholesterolemia. N Engl J Med. https://doi.org/10.1056/NEJMoa1913805

Ray KK, Landmesser U, Leiter LA et al (2017) Inclisiran in patients at high cardiovascular risk with elevated LDL cholesterol. N Engl J Med 376:1430-1440. https://doi.org/10.1056/ NEJMoa1615758

Ray KK, Bays HE, Catapano AL et al (2019a) Safety and efficacy of bempedoic acid to reduce LDL cholesterol. N Engl J Med 380:1022-1032. https://doi.org/10.1056/NEJMoa1803917 
Ray KK, Stoekenbroek RM, Kallend D et al (2019b) Effect of 1 or 2 doses of inclisiran on low-density lipoprotein cholesterol levels: one-year follow-up of the ORION-1 randomized clinical trial. JAMA Cardiol 4(11):1067-1075. https://doi.org/10.1001/jamacardio.2019.3502

Ray KK, Wright RS, Kallend D et al (2020) Two phase 3 trials of Inclisiran in patients with elevated LDL cholesterol. N Engl J Med. https://doi.org/10.1056/NEJMoa1912387

Ridker PM (2014) LDL cholesterol: controversies and future therapeutic directions. Lancet 384:607-617. https://doi.org/10.1016/S0140-6736(14)61009-6

Robinson JG, Nedergaard BS, Rogers WJ et al (2014) Effect of evolocumab or ezetimibe added to moderate- or high-intensity statin therapy on LDL-C lowering in patients with hypercholesterolemia: the LAPLACE-2 randomized clinical trial. JAMA 311:1870-1882. https://doi.org/10. 1001/jama.2014.4030

Robinson JG, Farnier M, Krempf M et al (2015) Efficacy and safety of alirocumab in reducing lipids and cardiovascular events. N Engl J Med 372:1489-1499. https://doi.org/10.1056/ NEJMoa1501031

Robinson JG, Rosenson RS, Farnier M et al (2017) Safety of very low low-density lipoprotein cholesterol levels with alirocumab: pooled data from randomized trials. J Am Coll Cardiol 69:471-482. https://doi.org/10.1016/j.jacc.2016.11.037

Roeters van Lennep J, Averna M, Alonso R (2015) Treating homozygous familial hypercholesterolemia in a real-world setting: experiences with lomitapide. J Clin Lipidol 9:607-617. https:// doi.org/10.1016/j.jacl.2015.05.001

Roth EM, McKenney JM (2015) ODYSSEY MONO: effect of alirocumab 75 mg subcutaneously every 2 weeks as monotherapy versus ezetimibe over 24 weeks. Futur Cardiol 11:27-37. https:// doi.org/10.2217/fca. 14.82

Roth EM, McKenney JM, Hanotin C, Asset G, Stein EA (2012) Atorvastatin with or without an antibody to PCSK9 in primary hypercholesterolemia. N Engl J Med 367:1891-1900. https://doi. org/10.1056/NEJMoa1201832

Russell C, Sheth S, Jacoby D (2018) A clinical guide to combination lipid-lowering therapy. Curr Atheroscler Rep 20:19. https://doi.org/10.1007/s11883-018-0721-2

Sabatine MS, Giugliano RP, Wiviott SD et al (2015) Efficacy and safety of evolocumab in reducing lipids and cardiovascular events. N Engl J Med 372:1500-1509. https://doi.org/10.1056/ NEJMoa1500858

Sabatine MS, Giugliano RP, Keech AC et al (2017a) Evolocumab and clinical outcomes in patients with cardiovascular disease. N Engl J Med 376:1713-1722. https://doi.org/10.1056/ NEJMoa1615664

Sabatine MS, Leiter LA, Wiviott SD et al (2017b) Cardiovascular safety and efficacy of the PCSK9 inhibitor evolocumab in patients with and without diabetes and the effect of evolocumab on glycaemia and risk of new-onset diabetes: a prespecified analysis of the FOURIER randomised controlled trial. Lancet Diabetes Endocrinol 5:941-950. https://doi.org/10.1016/S2213-8587 (17)30313-3

Sabatine MS, De Ferrari GM, Giugliano RP et al (2018) Clinical benefit of evolocumab by severity and extent of coronary artery disease. Circulation 138:756-766. https://doi.org/10.1161/ CIRCULATIONAHA.118.034309

Sahebkar A, Watts GF (2013) New LDL-cholesterol lowering therapies: pharmacology, clinical trials, and relevance to acute coronary syndromes. Clin Ther 35:1082-1098. https://doi.org/10. 1016/j.clinthera.2013.06.019

Sakamoto K, Kawamura M, Kohro T et al (2015) Effect of ezetimibe on LDL-C lowering and atherogenic lipoprotein profiles in type 2 diabetic patients poorly controlled by statins. PLoS One 10:e0138332. https://doi.org/10.1371/journal.pone.0138332

Santos RD, Duell PB, East C, Guyton JR, Moriarty PM, Chin W, Mittleman RS (2015) Long-term efficacy and safety of mipomersen in patients with familial hypercholesterolaemia: 2-year interim results of an open-label extension. Eur Heart J 36:566-575. https://doi.org/10.1093/ eurheartj/eht549 
Schwartz GG, Steg PG, Szarek M et al (2018) Alirocumab and cardiovascular outcomes after acute coronary syndrome. N Engl J Med 379:2097-2107. https://doi.org/10.1056/NEJMoa1801174

Seidah NG, Prat A, Pirillo A, Catapano AL, Norata GD (2019) Novel strategies to target proprotein convertase subtilisin kexin 9: beyond monoclonal antibodies. Cardiovasc Res 115:510-518. https://doi.org/10.1093/cvr/cvz003

Shiomi M, Ito T (2001) MTP inhibitor decreases plasma cholesterol levels in LDL receptordeficient WHHL rabbits by lowering the VLDL secretion. Eur J Pharmacol 431:127-131. https://doi.org/10.1016/s0014-2999(01)01419-4

Sirtori CR, Pavanello C, Bertolini S (2014) Microsomal transfer protein (MTP) inhibition-a novel approach to the treatment of homozygous hypercholesterolemia. Ann Med 46:464-474. https:// doi.org/10.3109/07853890.2014.931100

Sniderman AD, Tsimikas S, Fazio S (2014) The severe hypercholesterolemia phenotype: clinical diagnosis, management, and emerging therapies. J Am Coll Cardiol 63:1935-1947. https://doi. org/10.1016/j.jacc.2014.01.060

Stein EA, Dufour R, Gagne C et al (2012a) Apolipoprotein B synthesis inhibition with mipomersen in heterozygous familial hypercholesterolemia: results of a randomized, double-blind, placebocontrolled trial to assess efficacy and safety as add-on therapy in patients with coronary artery disease. Circulation 126:2283-2292. https://doi.org/10.1161/CIRCULATIONAHA.112. 104125

Stein EA, Gipe D, Bergeron J et al (2012b) Effect of a monoclonal antibody to PCSK9, REGN727/ SAR236553, to reduce low-density lipoprotein cholesterol in patients with heterozygous familial hypercholesterolaemia on stable statin dose with or without ezetimibe therapy: a phase 2 randomised controlled trial. Lancet 380:29-36. https://doi.org/10.1016/S0140-6736(12) 60771-5

Stein EA, Honarpour N, Wasserman SM, Xu F, Scott R, Raal FJ (2013) Effect of the proprotein convertase subtilisin/kexin 9 monoclonal antibody, AMG 145, in homozygous familial hypercholesterolemia. Circulation 128:2113-2120. https://doi.org/10.1161/CIRCULATIONAHA. 113.004678

Stitziel NO, Won HH, Morrison AC et al (2014) Inactivating mutations in NPC1L1 and protection from coronary heart disease. N Engl J Med 371:2072-2082. https://doi.org/10.1056/ NEJMoa1405386

Stitziel NO, Khera AV, Wang X et al (2017) ANGPTL3 deficiency and protection against coronary artery disease. J Am Coll Cardiol 69:2054-2063. https://doi.org/10.1016/j.jacc.2017.02.030

Stroes E, Colquhoun D, Sullivan D et al (2014) Anti-PCSK9 antibody effectively lowers cholesterol in patients with statin intolerance: the GAUSS-2 randomized, placebo-controlled phase 3 clinical trial of evolocumab. J Am Coll Cardiol 63:2541-2548. https://doi.org/10.1016/j.jacc.2014.03. 019

Sullivan D, Olsson AG, Scott R et al (2012) Effect of a monoclonal antibody to PCSK9 on low-density lipoprotein cholesterol levels in statin-intolerant patients: the GAUSS randomized trial. JAMA 308:2497-2506. https://doi.org/10.1001/jama.2012.25790

Taha DA, De Moor CH, Barrett DA, Gershkovich P (2014) Translational insight into statin-induced muscle toxicity: from cell culture to clinical studies. Transl Res 164:85-109. https://doi.org/10. 1016/j.trsl.2014.01.013

Tarugi P, Bertolini S, Calandra S (2019) Angiopoietin-like protein 3 (ANGPTL3) deficiency and familial combined hypolipidemia. J Biomed Res 33:73-81. https://doi.org/10.7555/JBR.32. 20170114

Taylor F, Huffman MD, Macedo AF et al (2013) Statins for the primary prevention of cardiovascular disease. Cochrane Database Syst Rev 1:CD004816. https://doi.org/10.1002/14651858. CD004816.pub5

Thompson PD, Rubino J, Janik MJ, MacDougall DE, McBride SJ, Margulies JR, Newton RS (2015) Use of ETC-1002 to treat hypercholesterolemia in patients with statin intolerance. J Clin Lipidol 9:295-304. https://doi.org/10.1016/j.jacl.2015.03.003

Thompson PD, MacDougall DE, Newton RS et al (2016) Treatment with ETC-1002 alone and in combination with ezetimibe lowers LDL cholesterol in hypercholesterolemic patients with or 
without statin intolerance. J Clin Lipidol 10:556-567. https://doi.org/10.1016/j.jacl.2015.12. 025

Tikka A, Jauhiainen M (2016) The role of ANGPTL3 in controlling lipoprotein metabolism. Endocrine 52:187-193. https://doi.org/10.1007/s12020-015-0838-9

Toda Kato E, Giugliano RP, Blazing MA et al (2015) Benefit and safety of adding ezetimibe to statin therapy on cardiovascular outcomes in 4416 women in the IMPROVE-IT trial. Circulation 132:A17862

Tonelli M, Lloyd A, Clement F et al (2011) Efficacy of statins for primary prevention in people at low cardiovascular risk: a meta-analysis. CMAJ 183:E1189-E1202. https://doi.org/10.1503/ cmaj. 101280

Toth PP (2013) Emerging LDL therapies: mipomersen-antisense oligonucleotide therapy in the management of hypercholesterolemia. J Clin Lipidol 7:S6-S10. https://doi.org/10.1016/j.jacl. 2013.02.004

Toth PP, Farnier M, Tomassini JE, Foody JM, Tershakovec AM (2016) Statin combination therapy and cardiovascular risk reduction. Futur Cardiol 12:289-315. https://doi.org/10.2217/fca-20150011

Tuteja S, Duffy D, Dunbar RL, Movva R, Gadi R, Bloedon LT, Cuchel M (2014) Pharmacokinetic interactions of the microsomal triglyceride transfer protein inhibitor, lomitapide, with drugs commonly used in the management of hypercholesterolemia. Pharmacotherapy 34:227-239

Visser ME, Wagener G, Baker BF et al (2012) Mipomersen, an apolipoprotein B synthesis inhibitor, lowers low-density lipoprotein cholesterol in high-risk statin-intolerant patients: a randomized, double-blind, placebo-controlled trial. Eur Heart J 33:1142-1149. https://doi.org/ 10.1093/eurheartj/ehs023

Wang DQ (2007) Regulation of intestinal cholesterol absorption. Annu Rev Physiol 69:221-248. https://doi.org/10.1146/annurev.physiol.69.031905.160725

Wang LJ, Song BL (2012) Niemann-pick C1-like 1 and cholesterol uptake. Biochim Biophys Acta 1821:964-972. https://doi.org/10.1016/j.bbalip.2012.03.004

Wang Y, Gusarova V, Banfi S, Gromada J, Cohen JC, Hobbs HH (2015) Inactivation of ANGPTL3 reduces hepatic VLDL-triglyceride secretion. J Lipid Res 56:1296-1307. https://doi.org/10. 1194/jlr.M054882

Wetterau JR, Gregg RE, Harrity TW et al (1998) An MTP inhibitor that normalizes atherogenic lipoprotein levels in WHHL rabbits. Science 282:751-754

Wiviott SD, Giugliano RP, Blazing MA et al (2015) Reduction in non-hemorrhagic stroke with Ezetimibe/simvastatin compared with simvastatin alone in the IMPROVE-IT trial. Circulation 132:A19694

Open Access This chapter is licensed under the terms of the Creative Commons Attribution 4.0 International License (http://creativecommons.org/licenses/by/4.0/), which permits use, sharing, adaptation, distribution and reproduction in any medium or format, as long as you give appropriate credit to the original author(s) and the source, provide a link to the Creative Commons licence and indicate if changes were made.

The images or other third party material in this chapter are included in the chapter's Creative Commons licence, unless indicated otherwise in a credit line to the material. If material is not included in the chapter's Creative Commons licence and your intended use is not permitted by statutory regulation or exceeds the permitted use, you will need to obtain permission directly from the copyright holder.

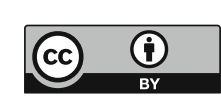

